\title{
Breve ensayo comparativo de la legislación salvadoreña y los convenios fundamentales de la OIT Hacia una política de defensa de los derechos laborales y las libertades sindicales
}

Amílcar Efrén Cardona Monterrosa

\section{A manera de prefacio}

Los tiempos son actuales difíciles, de dura crisis económica para El Salvador, y ello trae consigo serias consecuencias en el ámbito laboral. Los funcionarios gubernamentales y los tecnócratas de la empresa privada, reiteran con demasiada vehemencia a la opinión pública la necesidad de "evitar que nos deje el tren de la bistoria", teniendo la oportunidad de embarcar al país en un proyecto de globalización, de desarrollo de un área de libre mercado, llámese Tratado de Libre Comercio (TLC o NAFTA), Plan Puebla Panamá (PPP), Área de Libre Comercio de las Américas (ALCA), u otra denominación.

Lo cierto es que para las trabajadoras y trabajadores, los actuales son tiempos definidos por el modelo neoliberal que ha establecido una clara línea respecto de los derechos laborales y libertades sindicales; estos se caracterizan por la precarización del empleo, la flexibili- 
dad laboral, el manejo cada vez más hegemónico de las empresas transnacionales, la significativa presencia de la maquila textil -como propuesta de empleo y desarrollo*2, la privatización de los servicios públicos, el debilitamiento de la institucionalidad del Ministerio de Trabajo y Previsión Social, el paulatino desaparecimiento de la contratación colectiva, y la muerte provocada del movimiento sindical.

Sin embargo, en medio de este panorama nada halagador para el movimiento sindical salvadoreño, existe en su interior una preocupación por hacer un ejercicio de defensa de los derechos laborales y libertades sindicales, lo cual pasa necesariamente por una actitud de resistencia ante el embate implementado por un sector del empresariado nacional y transnacional, de allí surgen preguntas tales como: ¿Qué hacer en estos tiempos para defender legalmente la institucionalidad sindical? ¿Qué recursos y soportes legales - sean éstos nacionales o internacionales- se tienen para hacer valer los referidos derechos? ¿qué limitantes legales existen para el desarrollo y avance del derecho laboral en El Salvador? ¿Cómo entrar en la dinámica de la globalización y sus secuelas, sin perder la existencia de un movimiento sindical fuerte? ¿A qué argumentaciones se pueden recurrir como organización sindical de cara a la defensa de los derechos? El presente ensayo pretende de una manera breve pero sustancial, ofrecer algunas luces que permitan a los líderes y lideresas sindicales generar un debate en torno a estas y otras cuestionantes, y procurar la gestación de ideas novedosas que atiendan a la sobrevivencia y desarrollo del movimiento sindical salvadoreño.

En la línea ya señalada, se presenta a continuación un marco de referencia comparativo del derecho laboral vigente en El Salvador, y las normas fundamentales de la Organización Internacional del Trabajo (en adelante "OIT"), en materia de:

- Abolición del trabajado forzoso en el empleo;

- De la igualdad de remuneración de la mano de obra masculina y femenina, por trabajo de igual valor;

- Discriminación en materia de empleo y ocupación;

- Edad minima de admisión al empleo y las peores formas de trabajo infantil; $y$

- Libertad sindical y negociación colectiva. 
El abordaje de estos aspectos del derecho internacional del trabajo tiene una particularidad estratégica: se refieren a temáticas álgidas de atención, dado que su naturaleza y contenido implican necesariamente aspectos que no pueden, ni deben ser pasados por alto en el marco del derecho laboral del país.

En el desarrollo del presente ensayo, no solo se hace referencia a la naturaleza de cada uno de los derechos implícitos en los Convenios de la OIT que al respecto se citan, sino que se acotan las necesarias referencias a la concordancia o divergencia que con el derecho laboral nacional existen. Lo anterior se ve respaldado con datos obtenidos de una rápida investigación de campo realizada al respecto de sustentar afirmaciones incluidas en este ensayo.

El movimiento sindical salvadoreño en particular, $y$ latinoamericano en general, deben poner atención a la institucionalización del irrespeto de los derechos laborales - sean estos individuales o colectivos-, dado que allí se va perfilando el avance o retroceso de su existencia y razón de ser. La existencia de una violación sistemática de los derechos laborales y libertades sindicales, sin una reacción oportuna, madura y firme del movimiento sindical, abona la posibilidad de su desaparición, lo cual traerá consigo la vigencia de las reglas del mercado como norma privilegiada del "nuevo orden de las relaciones laborales".

La existencia y avance del sindicalismo es necesario e indispensable en el proceso de madurez de la incipiente democracia salvadoreña. La postulación e implementación de dogmas de mercado como el absoluto a considerar, puede causar mal versiones en el ámbito del derecho laboral, lo cual pudiese generar resentimientos y violencia. Ello debe evitarse adoptando para sí reglas del juego claras que garanticen el respeto y desarrollo de los derechos laborales y libertades sindicales, sustentado en criterios emanados de la normativa internacional del trabajo que sostiene que "una paz universal y duradera puede establecerse solamente si se basa en la justicia social"3.

\section{2. ¿De qué legislación laboral estamos hablando en El Salvador?}

Es pertinente antes de empezar a abordar lo relativo al derecho internacional del trabajo, en el contenido de los convenios de la OIT que son de competencia de estudio en este ensayo, establecer muy 
brevemente cual es marco de legislación laboral que se aplica en El Salvador.

\subsection{De la evolución constitucional}

En el marco constitucional, El Salvador ha tenido a lo largo de su historia independiente un total de 12 Constituciones - la primera en 1824, y la última de 1983 - las cuales han recibido en su momento diferentes nominaciones.

Pero fue hasta el año de 1950, cuando el derecho laboral adquiere un estatus constitucional; es a partir de ahí que se le contextualiza en el marco de los derechos sociales. La Constitución de 1950 señalaba en su Título XI, Capítulo II, lo relativo al Derecho del Trabajo como un componente del derecho social (Art. 182 al 196), allí se establecía que el trabajo es una función social y que lo atinente a su regulación se abordaría en un código de trabajo, empezando a establecer en el Art. 183 toda una gama de derechos individuales.

Actualmente, la Constitución de la República de El Salvador, promulgada por la Asamblea Constituyente el 15 de diciembre de 1983, establece en el Capítulo II lo relativo a los derechos sociales y la sección segunda lo atiende a Trabajo y Seguridad Social (Art. 37 al 52). A lo largo de 16 artículos, se establece un conjunto de derechos laborales de carácter individual, colectivo, de previsión social y procesal que son desarrollados en el Código de Trabajo.

\subsection{De la evolución legal}

El marco de referencia de la normativa secundaria es un tanto más amplia en su historia. El 1 de marzo de 1911 llega como presidente de El Salvador Manuel Enrique Araujo, y como lógica consecuencia de un pacto que este realizó con los obreros artesanos para acceder al poder, facilitó la creación de asociaciones artesanales, que es el génesis del actual movimiento sindical; se quitó la pena de cárcel por a existencia de deudas y se creó la "Ley de Accidentes del Trabajo" el 12 de mayo de 1911, que es la primera norma laboral que se creó en el país, a través de la cual por primera vez en la historia salvadoreña se obligaba al estado y a los empleadores a compartir la responsabilidad de indemnizar a las trabajadoras y trabajadores que sufrían accidentes de 
trabajo y quedaban incapacitados. Esta normativa sin embargo, no cubría a las trabajadoras y trabajadores rurales.

Entre los años de 1927 y 1928, como resultado de las presiones desarrolladas por la Federación Regional de Trabajadores de El Salvador (FRTS), se decretaron diferentes normas laborales, entre ellas "Ley de Registro de Agrupaciones Obreras y Gremiales"*5, la cual resulta la primera referencia que existe en la historia salvadoreña sobre normas sindicales. En 1946 se decretó la "Ley General sobre Conflictos Colectivos de Trabajo"*6, que consagró para esta clase de conflictos laborales un procedimiento específico.

Es digna de tener en consideración "La Ley de Sindicatos de Trabajadores" que data del 13 de agosto de 1951, y "La ley de Contratación Colectiva" que data del 27 de marzo de 1952.

El 14 de octubre de 1946 fue emitido el Decreto Legislativo No. 134 por medio del cual se creaban tres Ministerios de Estado, a saber: el Ministerio de Trabajo y Previsión Social, el Ministerio de Asistencia Social y el Ministerio de Agricultura e Industria. Dicho Decreto constituye la partida de nacimiento del Ministerio de Trabajo y Previsión Social $* 7$. En el lapso de octubre de 1946 a diciembre de 1948, el Presidente de la República Gral. Salvador Castaneda Castro nombró a 4 Ministros de Trabajo diferentes, lo cual indica lo difícil que fue iniciar el trabajo en dicha cartera de Estado; como lógica consecuencia de lo anterior creación, el reto inmediato fue la creación de un Código de Trabajo.

En Código de Trabajo que actualmente está vigente en El Salvador data del 23 de junio de 1972, elaborado en los tiempos del presidente Fidel Sánchez Hernández. Esta ley ha sido reformada en 9 ocasiones, la última a razón de una propuesta emanada luego de la firma de los Acuerdos de Paz.

El Código de Trabajo vigente es el segundo que tiene el país, el primero data del año 1962 y fue modificado a propósito de un proceso de mayor organización y desarrollo de las relaciones laborales a fines de la década de los sesenta.

De esta simple referencia histórica, muy breve por cierto, se puede concluir que no existe dentro de El Salvador un marco normativo laboral suficientemente actualizado que pueda responder a la vigencia y res-

391

Hacia una política de delensa 
peto de los derechos individuales y colectivos de los trabajadores y trabajadoras; y lo que es más grave, los procedimientos que en él se establecen tienen más de 30 años, de alli su lentitud y poca eficacia.

De lo referido arriba resultará compresible en adelante que no se va a identificar suficiente concordancia legal y práctica entre las disposiciones emanadas de la OIT y la Legislación vigente en El Salvador.

Pero lo mas grave no es la falta de adecuación legal de la normativa laboral salvadoreña, sino el hecho que debido a la ausencia de referentes legales suficientemente firmes en materia de trabajo los abusos se van institucionalizando. Esta afirmación no es ligera ni atrevida, por ello a lo largo de este ensayo no solo se hará la necesaria concordancia legal entre el contenido de los convenios de la OIT y la normativa salvadoreña, sino que se presentarán de manera escueta una serie de datos y de hechos que dan contenido a la preocupación señalada.

3. Del marco comparativo de los Derechos Laborales en la Legislación Salvadoreña y en los Convenios Fundamentales de la de la OIT

A continuación se pasa a abordar 5 temas fundamentales del derecho internacional del trabajo, los cuales ya fueron enunciados en la parte introductoria de este ensayo. La atención a cada una de las temáticas tiene un marco lógico idéntico, a saber: primero, la referencia a los Convenios de la OIT; segundo, la referencia al marco normativo salvadoreño en el cual se expone postura equivalente a lo que dispone la OIT, se evidencian las diferencias. Estos dos apartados concluyen con la presentación de un cuadro sinóptico que sirve de matriz comparativa entre la normativa internacional y la nacional; y finalmente, cuando ello ha sido posible se presentan datos recientes de la realidad laboral salvadoreña respecto de cada uno de los ejes temáticos. Esto último se considero pertinente dado que no basta hacer una comparación jurídica en abstracto, es pertinente y valioso cotejar el cumplimiento o no del marco normativo que rige la vida de un Estado.

\subsection{Abolición del trabajado forzoso en el empleo}

Los convenios 29 y 105 de la OIT abordan lo relativo a la abolición del trabajo forzoso u obligatorio. 
El Convenio 29 fue aprobado en la décima cuarta reunión de la OIT celebrada en Ginebra del 10 al 28 de junio de 1930, y entró en vigor a partir del 1 de mayo de 1932 . Este ha sido ratificado por El Salvador, así consta en el Decreto Legislativo No. 72 emitido por la Asamblea Legislativa de la República de El Salvador, el 14 de julio de 1994 y ratificado por el Presidente de la República Dr. Armando Calderón Sol, el 27 de julio de 1994. Este acuerdo fue publicado en el Diario Oficial número 155, Tomo 324, de fecha 24 de agosto de 1994. A lo largo de 33 artículos, la OIT establece una serie de valoraciones al respecto del trabajo forzoso u obligatorio.

En el cuadro sinóptico que se presenta al final de este apartado se establecen 12 de los aspectos más relevantes que se abordan en este Convenio. Partiendo primero de la obligación de los Estados que lo ratifiquen de abolir con prontitud el trabajo forzoso. La definición necesaria de trabajo forzoso u obligatorio esta comprendida en los artículos 1 y 2 del convenio ya citado

El convenio 105 de la OIT, relativo a la abolición del trabajo forzoso fue emitido en la cuadragésima reunión del organismo, celebrada en Ginebra entre el 5 y 27 de junio de 1957, entró en vigor a partir del 17 de enero de 1959. Este ha sido ratificado por El Salvador, así consta en el Decreto Legislativo No. 2647 emitido por la Asamblea Legislativa de la República de El Salvador, el 15 de mayo de 1958 y ratificado por el Presidente de la República, José María Lemus, el 20 de mayo de 1958. Este acuerdo fue publicado en el Diario Oficial número 98, Tomo 179, de fecha 29 de mayo de 1958.

El Convenio 29 de la OIT,' establece de manera detallada el contenido del trabajo forzoso u obligatorio y las excepciones que pueden haber al respecto. La Constitución de la República de El Salvador en el Artículo 4 recoge el espíritu de esa prohibición que esta minuciosamente desarrollada en el Convenio 29 de OIT y escueta pero categóricamente establecida en el Convenio 105 de la misma Organización Internacional. El artículo ya citado reconoce que toda persona es libre en este país y de que nadie puede ser sometido a servidumbre o esclavitud de ninguna condición que menoscabe su dignidad. Pero, sin dudas es el Art. 9 de la misma Carta Magna el que retoma claramente la prohibición del convenido 105 de la OIT cuando dice: "Nadie puede ser obligado ba realizar trabajos o prestar servicios personales sin justa 
retribución y sin su pleno consentimiento, salvo en los casos de calamidad pública y en los demás señalados por la ley".

En concordancia con las disposiciones constitucionales citadas el Art. 13 del Código de Trabajo señala: "Nadie puede impedir el trabajo a los demás sino mediante resolución de autoridad competente encaminada a tutelar los derechos de los trabajadores, de los patronos o de la sociedad, en los casos previstos por la Ley.

No se podrá hacer uso de ninguna forma de trabajo forzoso $u$ obligatorio, es decir de cualquier trabajo o servicio exigido bajo la amenaza de una pena cualquiera y para el cual el trabajador no se ba ofrecido voluntariamente.

La probibición a que se refiere el inciso anterior no comprende:

a) Cualquier trabajo o servicio que se exija en virtud de las leyes sobre el servicio militar obligatorio y que tenga un carácter puramente militar;

b) Cualquier trabajo o servicio que forme parte de las obligaciones civicas normales;

c) Cualquier trabajo o servicio que se exija en virtud de una condena pronunciada por sentencia judicial, a condición de que este trabajo o servicio se realice bajo la vigilancia y control de las autoridades públicas y que la persona que lo preste no sea cedido o puesto a disposición de particular, compañia o personas jurídicas de carácter privado;

cb) Cualquier trabajo o servicio que se exige en casos fuerza de mayor, es decir, guerra, siniestros o amenaza de siniestros, tales como: incendios, inundaciones, hambre, temblores de tierra, epidemias y epizootias violentas, invasiones de animales, de insectos o de parásitos vegetales dañinos, $y$ en general todas las circunstancias que pongan en peligro o amenacen pone en peligro la vida o las condiciones normales de existencia de toda o parte de la población;

d) Los pequeños trabajos comunales, realizados por los miembros de una comunidad en beneficio directo de la misma, a condición de que los miembros de la comunidad tengan derecho a pronunciarse sobre la necesidad de los mismos".

Este artículo es claro respecto de la prohibición del trabajo obligatorio y los casos de excepción que existen. En la legislación salvadore- 
ña los casos de excepción están referidos al trabajo penitenciario que esta contenido en el Capítulo III, "Trabajo Penitenciario", que es parte de la estructura de la Ley Penitenciaria.

Para el caso, entre los artículos 105 y 107 se establece la naturaleza del trabajo que van realizar las y los internos que están en los Centros Penales, siendo rasgo característico de las referidas labores que no deben de ser de carácter aflictivo, dado que su finalidad es mantener o aumentar la formación y conservación de hábitos laborales dentro de los internos y la rehabilitación de estos mismos, actividad que idealmente debe redundar en la dotación de algún ingreso económico para los que realizan tal trabajo.

En el caso de las y los internos hay obligatoriedad legal de desarrollar algún tipo de labor; por ejemplo, se señala que en los Centros Penitenciarios donde existen tierras disponibles para el cultivo, se debe organizar al interior de los mismos diferentes cuadrillas de internos que tienen la obligación de desarrollar trabajos agrícolas de cuyas cosechas que puedan ayudar a la alimentación del lugar, todo en el marco del reglamento del Centro Penitenciario.

Las labores artesanales que desarrollan las y los internos de los centros penales van también encaminadas a percibir algún tipo de ingreso para estos, así lo señala el Art. 106, No. 3; 109 y 110 de la Ley Penitenciaria. Este aspecto coincide con lo que dispone el Art. 14 del Convenio 29 de la OIT, en el sentido de que en la realización de estos trabajo forzosos debe haber una remuneración que no debe ser menor al salario mínimo. En el Ministerio de Trabajo y Previsión Social no se cuenta con información respecto de las condiciones de rehabilitación penitenciaria.

Finalmente, el Convenio 29 de la OIT en su Art. 24 establece como condición en la realización de trabajos obligatorios de utilidad pública, el respeto y garantía de los reglamentos relativos al empleo y trabajo forzoso u obligatorio. Así el artículo 112 y 113 de la Ley Penitenciaria establecen la adecuación reglamentaria de la autoridad competente para poder vigilar el cumplimiento de esta excepcionalidad de trabajo obligatorio. 


\section{ABOLICIÓN DEL TRABAJO FORZOSO EN EL EMPLEO ASPECTOS ABORDADOS NORMATIVA DE LA OIT LEGISLACIÓN SALVADOREÑA}

1. Obligación del Estado de suprimir con prontitud el empleo de trabajo forzoso u obligatorio

Convenio 29 OIT, Art. 1, No. 1

Convenio 105 OIT Art. 1. Art. 4 y 9

Constitución Art. 13 inc. $1^{\circ}$ y $2^{\circ}$ Código de Trabajo

2. Definición y delimitación de la expresión "trabajo forzoso u obligatorio"

Convenio 29 OIT, Art. 2, No. 1 y 2

Art. 13 inc. 3o. 29 No. 6 literal a) Código de Trabajo

3. La obligación de las autoridades competentes de no permitir que concesiones a particulares o personas jurídicas impliquen la imposición de cualquier forma de trabajo forzoso u obligatorio Convenio 29 OIT, Art. 4, No. 1 y 5

4. Casos en los cuales excepcionalmente se tolera el trabajo forzoso u obligatorio autorizado por jefes de administración pública y que impliquen la ejecución de trabajo de utilidad pública.

Convenio 29 OIT, Art. 10, No. 2. Art. 105 al 107. 111 Ley Penitenciaria

5. Categoría de personas que pueden ser sometidas a los casos excepcionales de trabajo forzoso u obligatorio

Convenio 29 OIT, Art. 11. Art. 108 Ley Penitenciaria

6. De los períodos máximos de tiempo en los cuales se puede estar sujeto a trabajo forzoso u obligatorio

Convenio 29 OIT, Art. 12

7. De los horarios de aquellos que están sujetos a la realización de trabajo forzoso u obligatorio

Convenio 29 OIT, Art. 13 
8. Del pago de salario por trabajo forzoso u obligatorio autorizados por el convenio

Convenio 29 OIT, Art. 14

Art. 109 y 110 Ley Penitenciaria

9. De la indemnización de los accidentes de trabajo o muerte de aquellos que realizan trabajo forzoso u obligatorio

Convenio 29 OIT , Art. 15

10. De la no adopción de traslado de personas dedicas al trabajo forzoso a regiones distintas a las de su origen, salvo condiciones excepcionales

Convenio 29 OIT, Art. 16

11. Garantizar la estricta aplicación de reglamentos relativos al empleo del trabajo forzoso u obligatorio

Convenio 29 OIT, Art. 24

Art. 112 y 113 Ley Penitenciaria

12. Sanciones penales por exigir ilegalmente forzoso $\mathrm{u}$ obligatorio Convenio 29 OIT Art. 25.

3.2. De la igualdad de remuneración de la mano de obra masculina y femenina, por trabajo de igual valor

En la trigésima cuarta reunión de la OIT sostenida en Ginebra entre 6 y 29 de junio de 1951 se a probó el convenio 100 relativo a la igualdad remuneración entre la mano de obra masculina y femenina por un trabajo de igual valor. Dicho convenio entró en vigor a partir del 23 de mayo de 1953. Esta norma internacional de trabajo ya fue ratificada por el Gobierno de El Salvador.

El Convenio 100 de la OIT adopta el criterio de la igualdad de remuneración entre la mano de obra masculina y femenina por un trabajo de igual valor, entonces aquí la dirección adoptada por la norma internacional va en un doble sentido, a saber: primero, a no establęcer una discriminación entre hombres y mujeres respecto del acceso al empleo y a la remuneración que se adquiera; y segundo, que la igualdad salarial entre hombres y mujeres sea igual por el desarrollo de un trabajo de igual valor. 
La normativa salvadoreña aún mantiene el criterio de igual remuneración a trabajo igual (Art. 38 , numerales $1^{\circ}, 2^{\circ}$, y $3^{\circ}$ de La Constitución), valoración que está ya superado por el convenio aquí referido.

Seguramente con par de ejemplos pueda clarificarse la afirmación anterior. Si hay dos personas, hombre y mujer, trabajando como vigilantes, a ambos les corresponde igual salario en base al criterio que establece la Constitución de la República _- “igual trabajo igual salario"-; pero pudiese darse el caso que se ofrecen dos empleos, de vigilante nocturno de una colonia, el cual se ofrece exclusivamente a hombres, y de empleada doméstica ofrecida a mujeres. Para ambos casos se van a requerir requisitos laborales que resultan ser equivalentes; por ejemplo, que ambos tengan estudios básicos, conocimientos específicos al área en la cual se van desempeñar al marco de responsabilidades, que sean mayores de edad, recomendaciones laborales, etc., entonces resulta que evidentemente estos trabajos no son iguales, pero dado que se establecen condiciones equivalentes, son trabajos de igual valor, y les corresponde la obtención de igual salario.

El Gobierno de El Salvador no ha adoptado este criterio "de igualdad salarial por trabajo de igual valor" porque como se va acotar más adelante en el punto de discriminación en materia de empleo y ocupación, todavía existen en El Salvador dificultades para superar esa discriminación de empleo y ocupación, y con mucha razón el de igualdad salarial.

A pesar de haber buscado datos de la realidad laboral salvadoreña para sustentar este apartado, no existen en las estadísticas del Ministerio de Trabajo, nada al respecto.

IGUALDAD DE REMUNERACIÓN DE LA MANO DE OBRA MASCULINA Y LA FEMENINA, POR UN TRABAJO

DE IGUAL VALOR

\section{ASPECTOS ABORDADOS NORMATIVA DE LA OIT LEGISLACIÓN SALVADOREÑA}

1. Definición de "remuneración"

Convenio 100 OIT Art. 1 literal a) Art. 118 Código de Trabajo 
2. Definición de "igualdad de remuneración entre la mano de obra masculina y la mano de obra femenina por un trabajo de igual valor"

Convenio 100 OIT, Art. 1 literal b)

3. La obligación del Estado de adoptar métodos vigentes de fijación de tasas de remuneración en base al principio de igualdad de remuneración entre la mano de obra masculina y femenina por trabajo de igual valor

Convenio 100 OIT, Art. 2

4. La obligación del Estado de adoptar medidas para promover la evaluación objetiva de empleo

Convenio 100 OIT, Art. 3

5. La obligación del Estado de colaborar con las organizaciones de empleadores y de trabajadores, a fin de evitar la discriminación en el empleo

Convenio 100 OIT, Art. 4

\subsection{Discriminación en materia de empleo y ocupación}

Respecto a la discriminación en materia de empleo ocupación la norma internacional que rige tal aspecto es el Convenio 111 de la OIT nominado "Convenio Relativo a la Discriminación en Materia de Empleo y Ocupación”, el cual fue aprobado en la cuadragésima segunda reunión de la OIT celebrada en Ginebra entre el 4 y 25 de junio de 1958, entrando en vigor a partir del 15 de junio de 1960.

El referido convenio fue ratificado por El Salvador, así consta en el Decreto Legislativo No. 78, de fecha 14 de julio de 1994 y confirmado por el Poder Ejecutivo del Presidente Armando Calderón Sol, el 27 de julio de 1994 publicado en el Diario Oficial Número 157, Tomo 324 de fecha 26 de agosto de 1994. Esta ratificación sucedió en el contexto de la firma de los Acuerdos de Paz.

El referido convenio hace un planteamiento novedoso respecto de la definición del término "discriminación" y las implicaciones legạles que tiene al respecto.

El Art. 1 del referido convenio establece con precisión la delimitación de lo que se va a considerar como discriminación y lo que está fuera de tal considerando, a la vez que exige a partir de los artículos 2 
y 3, la obligación de los Estados partes a adoptar una política que promueva métodos que procuren la igualdad de oportunidades y trato en el empleo y la ocupación con el objeto de eliminar cualquier forma de discriminación.

La Constitución de la República de El Salvador respecto de la discriminación no establece una definición equivalente a lo que acota este convenio, sin embargo el artículo 3 de la Carta Magna salvadoreña, apunta: "Todas las personas son iguales ante la ley. Para el goce de derechos civiles no podrá establecer restricciones que se basen en diferencias de nacionalidad, raza, sexo o religión.

No se reconocen empleos ni privilegios bereditarios";

En este principio de igualdad constitucional esta comprendido implícitamente la existencia de la no discriminación; sin embargo en el Código de Trabajo se adopta el espíritu de lo que establece el convenio 111 de la OIT, a saber: primero, el Art. 12 del Código de Trabajo acota que "El Estado velará por el respeto de los principios de igualdad de oportunidades $y$ de trato en el empleo y la ocupación, incluyendo el acceso a la formación profesional". En este artículo se está consagrando además el principio de gratuidad en el sentido de que el Estado es el obligado a velar por la vigencia de la igualdad y oportunidades de trato en el empleo; más adelante se va apuntar la forma de cómo está aplicada tal obligación en la práctica de la situación de empleo en E1 Salvador.

Una segunda disposición legal que hace referencia a la no discriminación esta conceptualizada en el artículo 30 No. 5 del Código de Trabajo, en el marco de las prohibiciones de los empleadores la referida disposición legal señala: "Se probibe a los patronos: ... 5 $5^{\circ}$ ) Hacer por medios directos o indirectos, discriminaciones entre los trabajadores por su condición de sindicalizados o tomar represarias contra ellos por el mismo motivo". Aquí se establece una protección ante la discriminación por la condición de sindicado lo cual esta concebido en el artículo 1 numeral $1^{\circ}$ literal a) del Convenio 111 de la OIT.

Pero, es seguramente el numeral duodécimo del mismo ártículo 30 del Código de Trabajo dónde se hace la referencia más exacta al Convenio en comento, cuando apunta: "Se probibe a los patronos: ... 12\%) establecer cualquier distinción, exclusión o preferencia basada en motivos de raza, color, sexo, religión, opinión política, ascendencia nacional $u$ 
origen social, salvo las excepciones previstas por la ley con fines de protección de la persona del trabajador".

Y finalmente el Art. 205 literal c) de la Ley en comento establece: "Se probibe a toda persona: ... c) Hacer discriminaciones entre los trabajadores por razón de sus actividades sindicales o tomar represarias contra ellos por el mismo motivo". Esto confirma la postura del artículo 12 del Código de Trabajo referida a la protección respecto de la sindicación.

Lo dispuesto en este marco legal referido, a saber: el convenio 111 de lo OIT, Constitución de la República y Código de Trabajo, debe ser examinado a la luz de su aplicación, a fin de verificar si efectivamente el Ministerio de Trabajo y Previsión Social lleva una política nacional que promueva métodos que procuren la igualdad de oportunidades en el trato de empleo y ocupación.

La referida cartera de Estado de una manera timorata a adoptado algún tipo de medidas al respecto. En los registros del Ministerio de Trabajo no se lleva una estadística en la cual se distingan los diferentes fenómenos en materia laboral que se atienden, diferenciando por su género.

Hay en El Salvador un marcado nivel de discriminación en el ofrecimiento de empleo. Tal afirmación se vio respaldada por los resultados de una investigación de campo que implicó la lectura y verificación de los ofrecimientos de empleo en los dos periódicos de mayor circulación: La Prensa Gráfica, en el mes de junio; y El Diario de Hoy, en el mes de julio.

El objeto de tal verificación era examinar uno a uno todos los ofrecimientos de empleo que existían en los referidos periódicos a lo largo de 61 días, 30 de junio y 31 de julio del año 2002; y los resultados obtenidos son los siguientes: la variación de la publicación de anuncios va desde 134, que es el ofrecimiento menor de empleo que regularmente se publican los fines de semana, hasta 325 que se publican en una guía de empleo que uno de los matutinos ofrece los días lunes. En esta variación de anuncios el $30 \%$ no expresa ningún tipo de señálamiento de discriminación. El porcentaje más acentuado, es el $44 \%$ relativo a la discriminación por razón del sexo. Vale acotar al respecto algún tipo de ejemplo. Se señala en anuncios que se necesitan vigilantes y una condición para ello es que deben ser hombres; o el ofreci- 
miento de que se necesitan vendedores a condición de que deben de ser mujeres; se necesitan gerentes que deben de ser hombres.

Este condicionamiento de ser hombre o mujer, según el caso, para ser considerado como candidata o candidato válido para acceder a un empleo, cuando este puede ser desarrollado óptimamente por cualquiera de los dos, pone en evidencia que existe una discriminación por razón del sexo. Del $44 \%$ señalado el nivel de mayor discriminación es para las mujeres.

Un segundo nivel identificado en los anuncios periodísticos, es la discriminación en el empleo por razón de edad. El 18\% de los anuncios apunta que hay una condición de acceso de empleo dependiendo de la edad. Para el caso, el margen de edad para empleo de las mujeres anda entre los 18 y 28 años; mientras que para los hombres hay un margen que va desde los 18 a los 35 años de edad, de nuevo acá la discriminación mayor en razón de edad es para la mujer.

Un tercer nivel de discriminación se da razón de la práctica religiosa, este asciende al $5 \%$. En el porcentaje ya referido de anuncios se establece como condición para tener acceso al empleo pertenecer y llevar recomendación del pastor evangélico o del sacerdote en el cual se esta adscrito religiosamente.

Finalmente un 3\% de los anuncios clasificados hacen una discriminación por razón de estado civil. Para el caso se pone como condición para acceder al empleo de secretaria que sea mujer soltera, o para acceder al empleo de vendedora "ser señorita, no casadas y sin compromisos familiares". Esta resulta ser una discriminación por razón de su estado civil.

Un segundo elemento que se indagó en la investigación de campo realizada en los dos matutinos de mayor circulación fue la naturaleza de empleo que se ofrece en los medios de prensa. La mayor oferta en el país es para agentes de seguridad, en su mayoría exclusivamente para hombres. Un segundo empleo disponible que hay - con referencia exclusiva a la mujer - es la de empleada domestica, es decir para hacer labores propias de la casa; una tercer es el de vendedor o véndedora, hay mucha frecuencia el requerimiento de vendedores de libros y de productos de belleza. En un cuarto nivel esta el de mecánico, este es un ofrecimiento exclusivo para hombres; un quinto nivel el de cocinera $y$ finalmente un sexto nivel de ofrecimiento el de secretaria. 
En esta gama de ofrecimientos de empleo ${ }^{8}$, de los que resultan ser los mas reiterados, se evidencia una condición muy frecuente para todos: "que no haya problema de borario", "que no exista dificultad con la extensión de la jornada ordinaria de trabajo", "que se esté disponible a laborar en horarios flexibles". Estos agregados son sumamente preocupantes porque al final esta señalándose un claro rasgo de flexibilidad laboral en los nuevos empleos que aparecen ofertados en la prensa escrita de El Salvador. Esta política laboral alterará cualquier posibilidad de estudio, de atención de su casa, vida familiar o de vida personal que pueda tener la trabajadora o el trabajador, y obviamente de esta extensión de la jornada ordinaria no existe remuneración salarial adicional, y se vulnera abiertamente el derecho a una jornada ordinaria de trabajo de 8 horas diarias o 7 horas nocturnas.

El contenido del Convenio 111 de la OIT referido a la discriminación en materia de empleo y ocupación resulta ser una materia pendiente de observación, y adopción de una política adecuada del Estado salvadoreño, tendiente a asegurar la no existencia de la discriminación en empleo y ocupación.

\section{LA DISCRIMINACIÓN EN MATERIA \\ DE EMPLEO Y OCUPACIÓN}

\section{ASPECTOS ABORDADOS NORMATIVA DE LA OIT LEGISLACIÓN SALVADOREÑA}

1. De la definición del término "discriminación" e implicaciones legales de la misma

Convenio 111 OIT, Art. 1, literales a) y b) Art. 12. 30 No. 5 y 12. 205 literal c) Código de Trabajo

2. De lo que no se considera discriminación en el empleo. Convenio 111 OIT, Art. 1, No. 2, Art. 4, Art. 5 No. 2.

3. La obligación de los Estados a formular y llevar a cabo una política nacional que promueva métodos que procuren igualdad. de oportunidades y de trato de empleo y ocupación, con objeto de eliminar cualquier discriminación.

Convenio 111 OIT, Art. 2 y 3 
3.4. Edad mínima de admisión al empleo y las peores formas de trabajo infantil

Al respecto de este punto son los Convenios 138 y 182 de la OIT los que abordan lo atinente. En la quincuagésima octava reunión de la OIT celebrada en Ginebra entre el 6 y 27 de junio de 1973 se aprobó el convenio 138 nominado: sobre la edad minima de admisión al empleo; muchas de las disposiciones de la normativa salvadoreña que se citan a continuación retoman lo que dispone el citado Convenio.

El Convenio 138 de la OIT en su Art. 1 establece el compromiso de los Estados partes de seguir una política nacional que asegure la abolición del trabajo de las niñas y de los niños y a elevar progresivamente la edad minima de admisión al empleo. Esta disposición está retomada por lo que dispone el Art. 38 numeral $10^{\circ}$ de la Constitución donde se establece que los menores de catorce años de edad y los que babiendo cumplido esa edad sigan sometidos a la enseñanza obligatoria en virtud de la ley no pueden ser ocupados en ninguna clase de trabajo. Este mismo elemento es retomado en el Art. 114 del Código de Trabajo que establece una afirmación muy semejante a la citada.

En concordancia con el anterior, el Art. 380 del Código de Familia reafirma la posición del Estado salvadoreño no de abolir el trabajo de las niñas y de los niños, sino más bien evitar que estos laboren mientras están en edad de la educación formal.

El Art. 2 del Convenio en estudio, establece la obligación de especificar la edad minima de admisión de empleo. De acuerdo a la lectura del Art. 38 numeral $10^{\circ}$ de la Constitución, 114 del Código de Trabajo y 38 literal c) del Código de Familia, se puede establecer que bay una valoración del Estado salvadoreño que las niñas y niños a partir de los 14 años de edad pueden empezar a laborar previa autorización del Ministerio de Trabajo y Previsión Social, y a condición que se trate de trabajos ligeros. Este tipo de disposiciones reglamenta el trabajo infantil en lugar de abolirlo.

El Art. 3 del Convenio ya citado, acota que en condiciones laborales que resulten peligrosas para la salud, seguridad o la moralidad de los menores la edad minima de admisión al empleo no tiene que ser inferior a los 18 años. En esta dirección el Art. 38 numeral $10^{\circ}$ de la 
Constitución en el párrafo cuarto establece: "Se probibe el trabajo a los menores de 18 años y a las mujeres en labores insalubres peligrosas. También se probibe el trabajo nocturno a los menores de 18 años. La ley determinará las labores peligrosas o insalubres". Esta disposición es retomada en el Código de Trabajo en los incisos $1^{\circ}$ y $2^{\circ}$ del Art. 105, 106, 107 y 108. El Código de Familia en el Art. 351 numeral 11 y 380 literal d) establece la protección respecto de la no laboralidad de los menores de 18 años en condiciones peligrosas o insalubres.

El Convenio 138 en su Art. 6 enumera categorias que no se van a considerar como trabajo de los menores, baciendo referencia a labores en la que estos se ven vinculados en talleres, escuelas de enseñanza, instituciones de formación, etc. Esta misma valoración esta retomada en los Art. 61 al 70 del Código de Trabajo que es el apartado que rige lo relativo al trabajo de los aprendices. De igual forma el Código de Familia en sus Art. 380 literal b) y 382 abordan el mismo tópico.

Concatenado con lo anterior, este elemento del aprendizaje tiene relación directa con una ley especial que también reafirma la posibilidad de la formación profesional, la Ley de Formación Profesional $(\text { INSAFORP })^{* 9}$.

Finalmente hay otra cantidad de aspectos que están retomados en el convenio y que pueden ser identificados en el cuadro sinóptico que esta al final de este apartado, sin embargo vale hacer referencia al becho que las autoridades competentes deben de adoptar las medidas y sanciones necesarias para la aplicación efectiva de lo que dispone el Convenio 138 de la OIT, asi lo manda su Art. 9. Este viltimo aspecto esta retomado en los Art. 115, 116 y 117 del Código de Trabajo, y por igual existe una probibición respecto de la explotación de los menores y la mendicidad en el Código Penal.

Un segundo convenio que tiene pertinencia con el punto que se estudia es el 182: "Sobre la probibición de las peores formas de trabajo infantil y acción inmediata para su eliminación". Este convenio ha sido ratificado por El Salvador, a pesar de ello no existe referencia legal alguna en la legislación primaria y secundaria.

Pareciera que el Estado salvadoreño no esta por la adopción de una politica que se encamine a la abolición del trabajo de las niñas y de los niños, sino más bien el eliminar las peores formas de trabajo infantil y 
adoptando acciones inmediatas para su eliminación. Al respecto existe en el pais la implementación del Programa Internacional para la Erradicación del Trabajo Infantil (IPEC), auspiciado entre otros, con fondos de la OIT.

Se ban establecido en los mismos medios de comunicación, una serie de valoraciones vinculadas con las peores formas de trabajo infantil, $y$ vale en esta oportunidad hacer referencia a datos recientes que pueden ilustrar las condiciones del trabajo infantil y de las peores formas también existentes en El Salvador:10.

De acuerdo a datos del mismo IPEC, en El Salvador hay unos 170,000 niñas y niños que trabajan; según la Dirección General de Estadística y Censos (DIGESTIC) en el año 2001, un total de 56,271 niñas y niños se incorporaron al mercado de trabajo lo que representó un aumento del $34 \%$ respecto del año 2000 .

Según los datos de la DIGESTIC, para el 2001 había un total 222,254 menores que trabajan en El Salvador y los cuales aportan anualmente a sus familias 124 millones de dólares.

El $67 \%$ de las niñas y niños trabajadores laboran en el agro; hay unos 2,500 que están empleados en talleres artesanales elaborando productos pirotécnicos en las coheterías salvadoreñas. Cerca de un mil niños y niñas permanecen diariamente en los basureros del país haciendo trabajo de reciclaje, y 1,300 recolectan curiles en los pantanos de Jiquilisco y la zonas de manglares.

Para agosto del 2002, la Asamblea Legislativa preparaba la aprobación del Código de la Niñez y de la Adolescencia, la cual en el Art. 38 establecería ciertos derechos para los menores trabajadores, entre ellos el acceso al salario mínimo.

Los datos que se enuncian respecto del trabajo peligroso, y de los menores trabajadores que se consumen en tales circunstancias son escalofriantes, y debería poner en alerta al movimiento sindical, en el sentido que el futuro de un gran porcentaje de niñas y niños salvadoreños esta incierto desde ya. 


\section{DE LA EDAD MINIMA DE ADMISIÓN AL EMPLEO Y LAS PEORES FORMAS DE TRABAJO INFANTIL}

\section{ASPECTOS ABORDADOS NORMATIVA DE LA OIT LEGISLACIÓN SALVADOREÑA}

1. El compromiso del Estado seguir una política nacional que asegure la abolición del trabajo de los niños y niñas y elevar progresivamente la edad mínima de admisión al empleo o al trabajo Convenio 138 OIT, Art. 1 Art. 38, No. 10 Constitución Art. 114 Código de Trabajo Art. 380 Código de Familia

2. Cada Estado deberá especificar en una declaración anexa la edad mínima de admisión al empleo Convenio 138 OIT, Art. 2 Art. 38, No. 10 Constitución Art. 104.114 Código de Trabajo Art. 380 literal c) Código de Familia

3. En condiciones laborales que resulten peligrosas para la salud, la seguridad o moralidad de los menores, la edad mínima de admisión al empleo no será inferior a los 18 años Convenio 138 OIT, Art. 3 Art. 38 No. 10 Constitución Art. 105 inc. $1^{\circ}$ y $2^{\circ} 106.107 .108 .109,360$ Código de Trabajo Art. 351 No. 11 Y 380 literal d) Código de Familia

4. Si fuese necesario, la autoridad competente, previa consulta, puede excluir de la aplicación del convenio a categorías limitadas de empleos Convenio 138 OIT, Art. 4

5. Los Estados determinarán en una declaración anexa, las ramas de actividad económica o los tipos de empresas a los cuales se aplicarán las disposiciones del Convenio, pero se establecen ámbitos laborales en los cuales no se puede dejar de aplicar lo que allí se dispone Convenio 138 OIT, Art. 5.

6. Lo dispuesto en el Convenio no se aplica al trabajo efectuado por los niños y niñas en las escuelas de enseñanza general, profesional o en instituciones de formación

Convenio 138 OIT, Art. 6 
Art. 61 al 70

Art. 105 , inc. $4^{\circ}$ Código de Trabajo

Art. 380 literal b) y 382 Código de Familia

Art. 6 literales g) Ley de formación Profesional

7. La autorización para permitir el trabajo a los niños y niñas de 13 a 15 años en empleos ligeros y bajo la condición de cumplimiento de ciertas condiciones básicas

Convenio 138 OIT, Art. 7 Art. 38 No. 10 Constitución Art. 114 inc. $2^{\circ}$ Código de Trabajo.

Art. 380 Código de Familia.

8. La autorización de las autoridades competentes de excepción a la prohibición de ser admitido al empleo en representación artísticas Convenio 138 OIT, Art. 8 Art. 114 inc. $3^{\circ}$ y $4^{\circ}$ Código de Trabajo

9. Las autoridades competentes deben adoptar las medidas, $y$ sanciones necesarias para la aplicación efectiva de lo que dispone el presente convenio

Convenio 138 OIT, Art. 9 Art. 115. 116.117 Código de Trabajo

10. El compromiso del Estado de adoptar medidas inmediatas y eficaces para conseguir la prohibición y la eliminación de las peores formas de trabajo infantil

Convenio 182 OIT, Art. 1

11. De la definición del término "niño"

Convenio 182 OIT, Art. 2 Art. 345 Código de Familia

12. De lo que se considerará "peores formas de trabajo infantil" Convenio 182 OIT Art. 3 y 4

13. Del establecimiento o designación de mecanismos apropiados para vigilar la aplicación de disposiciones de este convenio, incluidas las acciones penales

Convenio 182 OIT, Art. 5 y 6 Art. 205 Código Penal

14. Elaborar y poner en práctica programas de acción para eliminar, como medida prioritaria las peores formas de trabajo infantil. Convenio 182 OIT Art. 6 


\subsection{Libertad sindical y negociación colectiva}

Hacer referencia a la libertad sindical y a la negociación colectiva en El Salvador resulta ser un aspecto sumamente delicado. Estos tópicos han traído roces, diferencias y escores entre el sector laboral organizado y el de empleadores a lo largo de la historia. De ahí que las afirmaciones que se hacen en este apartado van suficientemente sustentadas en el marco legal y de casos que respaldan las acotaciones que al respecto se hacen.

El tema de libertad sindical y negociación colectiva esta contenido en el marco del Derecho Internacional en los Convenios 87y 98 de la OIT, respectivamente, instrumentos en los cuales se reconoce sin exclusión alguna el ejercicio irrestricto de todas las trabajadoras y trabajadores al goce de la libertad sindical; entiéndase esta en sus tres facetas: derecho a la constitución y afiliación sindical, derecho a la negociación colectiva, y derecho a la huelga.

El tema de libertad sindical y negociación colectiva está incluido en variados convenios y recomendaciones que ha emitido la OIT a lo largo de su vida; sin embargo, en esta ocasión se abordarán solamente dos convenios, a saber: Convenio 87, "Relativo a la libertad sindical y a la protección al derecho de sindicación", y el Convenio 98, "Relativo a la aplicación de los principios del derecho de sindicación y negociación colectiva".

El Convenio 87 fue emitido en el contexto de la trigésima primera reunión de la OIT, celebrada en San Francisco, entre el 17 de junio y el 10 de julio de 1948, y entró en vigor el 4 de julio de 1950, hace exactamente 52 años. El Salvador aún no ha ratificado este Convenio, aduciendo que lo dispuesto en el mismo riñe con disposiciones constitucionales.

El Convenio 87 que puede ser citado como el "Convenio sobre la Libertad Sindical y la proyección del derecho de sindicación”, consagra el principio de la universalidad del derecho de sindicación, reza su Art. 2: "Los trabajadores y los empleadores sin ninguna distinción y sin autorización previa, tienen el derecho de constituir las organizaciones que estimen convenientes, a si como el de afiliarse a estas organizaciones, con la sola condición de observar los estatutos de las mismas". La Constitución de El Salvador, en el Art. 47 es clara al señalar que los empleadores, trabajadoras y trabajadores privados tienen ese derecho 
de asociarse libremente y, por extensión, la Constitución, al final del inciso $1^{\circ}$ del Art. 47 establece el mismo derecho para aquellas y aquellos que laboran en las instituciones oficiales autónomas.

Haciendo una interpretación restrictiva del derecho constitucional cotado, los funcionarios públicos y empresarios presentan una primera objeción que si la voluntad del constituyente hubiese sido que el derecho de sindicación estuviese reconocido a las trabajadoras y trabajadores del Estado, estaría consignado en ese mismo contexto del Art. 47, sin embargo no se dice; y es más -se argumenta a su favor-, se establece para las trabajadoras y trabajadores del Estado, un régimen laboral específico contenido en el Título VII de la Constitución "Del Régimen Administrativo", en su Capítulo I "Servicio Civil" (Art. 218 al 222 Cn.). Tomando en consideración esta lectura, El Salvador tiene constitucionalmente dos sistemas laborales completamente diferentes, a saber: el sistema del trabajo en la empresa privada y el sistema de trabajo en el sector público.

Una segunda objeción que reiteradamente se ha planteado para no ratificar el Convenio 87 de la OIT es que este señala que las trabajadoras y trabajadores por una parte, y los empleadores por la otra, pueden "... Constituir las organizaciones que estimen convenientes...”, dicha acotación es considerada por los actuales funcionarios del Ministerio de Trabajo como inconveniente, dado que según ellos la Constitución limita el derecho de asociación profesional para la defensa de los intereses profesionales comunes de las trabajadoras y trabajadores o de los patronos. La Constitución es precisa en el objeto que debe perseguir la asociación profesional, es decir el sindicato. No queda abierto para ningún otro tipo de finalidades.

Partiendo de las reglas de la hermenéutica jurídica hay que hacer una acotación más aguda que permita tener una perspectiva paralela a la que hacen los funcionarios del gobierno y algunos empresarios salvadoreños enunciada rápidamente arriba. El Convenio 87 de la OIT reconoce el amplio derecho de todas las trabajadoras y trabajadores a sindicalizarse, y no por ello no es contrario a la Constitución ${ }^{* 11}$.

La Carta Magna de El Salvador en el Art. 47, reconoce expresamente ese derecho a los sectores empleador, trabajadoras y trabajadores de la empresa privada y de las instituciones oficiales autónomas. En la parte relativa al servicio civil _- "Del Régimen Administrativo", 
cuando se refiere a libertad sindical, la única disposición atinente al caso es el Art. 221 de la Constitución, en la cual se prohíbe la huelga y el abandono colectivo de los cargos por parte de las trabajadoras y trabajadores públicos y municipales; a pesar de ello no existe ninguna prohibición expresa en cuanto al derecho de constitución sindical para este sector.

Para que las trabajadoras y trabajadores estatales se vieran impedidos de ejercer el ya referido derecho, sería indispensable que de manera expresa lo limitara la Constitución, por cuanto, tratándose de normas elementales sobre derechos humanos, la interpretación que debe hacerse de la disposición constitucional debe ser de carácter extensivo y no restrictivo; en ese sentido, si el ejercicio de un derecho individual no está prohibido ni restringido por la Constitución, el intérprete o el legislador secundario no tienen porque restringirlo en su aplicación práctica, siendo esto consonante con el Principio de Legalidad consagrado en el Art. 8 de la Constitución que reza: "Nadie está obligado a hacer lo que la ley no manda ni a privarse de lo que ella no probibe".

Por otra parte si bien el Art. 219 de la Constitución de la República de El Salvador establece la regulación del servicio civil por medio de una ley especial, de ninguna manera establece la regulación, limitación o exclusión del ejercicio de ese derecho fundamental, el de sindicación. La pretensión de este capítulo del "Servicio Civil" es sentar las bases necesarias para que el ingreso, promociones, deberes de las y los servidores públicos y régimen disciplinario obedezcan a normas técnicas y no a razones políticas, que es lo que se trata de evitar con quienes trabajan al servicio del Estado. Tal y como lo reafirma el Art. 218 de la misma norma en comento: "Los funcionarios y empleados públicos están al servicio del Estado y no de una fracción política determinada..."

Finalmente otro argumento que justifica la ratificación del Convenio 87 relativo al ejercicio del derecho de sindicación, es que El Salvador ya ratificó instrumentos de derecho internacional como la Declaración Universal de los Derechos Humanos (1948), el Pacto Internacional de Derechos Económicos, Sociales y Culturales (1948) y la Carta Internacional Americana de Garantías Sociales (Carta de Bogotá 1948) entre otros, en los cuales se reconoce ampliamente el derecho a la sindicación a todas las trabajadoras y trabajadores sin distinción alguna. 
Si existe una gama de instrumentos internacionales que respaldan tal postura, ¿cuál es la razón técnica para rechazar el Convenio 87 por el motivo de reconocer el derecho de organización sindical de forma amplia?. Esta negativa no tiene lógica a la luz de los compromisos internacionales que El Salvador ya tiene suscritos.

El otro convenio digno de atención en este apartado es el 98 "Relativo a la aplicación de los principios del derecho de sindicación y de negociación colectiva", este fue emitido en el marco de la trigésima primera reunión de la OIT, celebrada en San Francisco, entre el 17 de junio y el 10 de julio de 1948, y entró en vigor el 18 de julio de 1951, hace 51 años. El Salvador se ha negado reiteradamente a ratificar tal convenio.

Las objeciones a este Convenio 98 de la OIT caen por su peso; si El Salvador no reconoce el ejercicio irrestricto del derecho de sindicación, y este resulta por regla general una condición sine qua non para la negociación colectiva, entonces esta no se admite.

Cuando se firmaron los acuerdos de paz en el año de 1992, se instaló el Foro de Concertación Económica y Social dando cumplimiento a lo que dispone el capítulo VII de los referidos acuerdos, y en tal escenario uno de los aspectos que se abordo como pretensión del sector laboral fue la aprobación de una serie convenios de la OIT, entre los cuales se encontraban el 87 y $98^{* 12}$. En tal contexto, el sector de empleadores representados entre otros por la Asociación Nacional de la Empresa Privada (ANEP) y los representantes del gobierno mismo señalaron que no era posible la ratificación de los convenios 87 y 98 de la OIT dado que, estos implicaban la violación a disposiciones constitucionales. Luego entonces, esto requeriría desde la óptica estos actores el hacer reformas a la Constitución en los Artículos 47, 39 y 221 , dado que, en los referidos en ese orden, atañen lo relativo a la sindicación, a la negociación colectiva y al derecho de la huelga.

En el cuadro sinóptico que a continuación se presenta se establece un marco comparativo entre los derechos reconoce la normativa de la OIT y los derechos que reconoce la legislación salvadoreña en materia de libertad sindical, con la salvedad que hay que tomar en cuenta que la normativa de la OIT reconoce toda esta gama de derechos para todos y todas las trabajadoras y trabajadores sin distinción. Mientras 
que la legislación salvadoreña solo hace aquellos que laboran en las empresas privadas y autónomas.

\section{LIBERTAD SINDICAL Y NEGOCIACIÓN COLECTIVA ASPECTOS ABORDADOS NORMATIVA DE LA OIT LEGISLACIÓN SALVADOREÑA}

1. Derecho a la constitución de organizaciones sindicales Convenio 87 OIT, Art. 2 Art. 47, inc. $1^{\circ}$ Constitución Art.204.208.209.210.211.212.214 248. Código de Trabajo Art. 8 literal b). 22 literal b), Ley de Organización y Funciones del Sector Trabajo y Previsión Social

2. Derecho a la afiliación sindical

Convenio 87 OIT, Art. 2 Art. 210.229, literal ch). 253-254, Código de Trabajo

3. Derecho a redactar los estatutos sindicales

Convenio 87 OIT, Art. 3, No. 1 Art. 215.217.218.260 Código de Trabajo

4. Derecho a elegir libremente a los representantes de su organización sindical

Convenio 87 OIT, Art. 3, No. 1 Art. 47 inc. $4^{\circ}$ Constitución Art. 213 literal c) 220 al 227 Código de Trabajo

5. Derecho a organizar la administración, actividades y programas de acción sindical

Convenio 87 OIT, Art. 3, No. 1 Art. 226.228.261

Código de Trabajo

6. Derecho a que las autoridades públicas no intervengan limitando o entorpeciendo el ejercicio legal de las organizaciones sindicales Convenio 87 OIT, Art. 3, No. 2. Art. 256 Código de Trabajo

7. Derecho a la no disolución o suspensión administrativa de las organizaciones sindicales

Convenio 87 OIT, Art. 4 Art. 47 inc. $2^{\circ}$ Constitución Art. 232.233.619 Código de Trabajo

8. Derecho a constituir federaciones y confederaciones sindicales Convenio 87 OIT, Arts. 5 y 6. Art. 257 al 263 Código de Trabajo 
9. Derecho a la afiliación a organizaciones internacionales sindicales Convenio 87 OIT , Art. 5

10. Derecho a afiliarse a las federaciones y confederaciones sindicales Convenio 87 OIT, Art. 5 Art. 262 Código de Trabajo

11. Derecho a la obtención de la personalidad jurídica de las organizaciones sindicales

Convenio 87 OIT, Art. 7 Art. 47, inc. $2^{\circ}$ Constitución Art. 216.219 Código de Trabajo

12. Derecho a gozar de una adecuada protección contra todo acto de discriminación tendiente a menoscabar la libertad sindical

Convenio 98 OIT Art. 1, No. 1 y 2 Art. 47 inc. $4^{\circ}$ Constitución Art. 248.249.250 Código de Trabajo

Art. 246 Código Penal.

13. Derecho a ser protegido de actos de injerencia en su constitución, funcionamiento o administración sindical

Convenio 98 OIT, Art. 2 Art. 205 Código de Trabajo Art. 247 Código Penal

14. Derecho a ser protegido por organismos nacionales que garanticen el respeto al derecho de sindicación

Convenio 98 OIT Art. 3 Art. 251 Código de Trabajo

15. La adopción de medidas adecuadas que procuren procedimientos de negociación voluntaria, con objeto de reglamentar, por medio de contratos colectivos las condiciones de empleo Convenio 98 OIT Art. 4 Art. 39 Constitución Art. 269 al 294.480 al 566 Código de Trabajo Art. 8 literal c) y d). 22 literales c), d), e), f) Ley de Organización y Funciones del Sector Trabajo y Previsión Social

A razón de ser precisos en el marco conceptual, hay que decir, que la Constitución de la República de El Salvador no prohíbe la sindicación de las trabajadoras y trabajadores del sector público, ni la negociación colectiva para estos, simplemente de manera expresa reconoce, tal facultad para quienes laboran en las empresas privadas o instituciones oficiales autónomas que dicho sea de paso estos últimos también son trabajadoras y trabajadores públicos. Pero, a pesar que se ha reconocido tal derecho para este último sector citado, hay una innumera 
ble cantidad de casos en los cuales se establece una violación al derecho de constitución de las organizaciones sindicales.

Pero la dificultad en El Salvador no es solo relativa a la no ratificación de Convenios Internacionales de la OIT en materia de libertad sindical y negociación colectiva, sino a la existencia de una cultura antisindical en el país, la cual esta institucionalizada en el mismo Ministerio de Trabajo y Previsión Social. De allí que se ha llegado al acabose de que no es posible en El Salvador ni siquiera el cumplimiento de la normativa laboral. Esta afirmación es radical y hay que probarla. Se presentan a continuación 5 bloques de violaciones a la libertad sindical y a la negociación colectiva..

El convenio 87 de la OIT en el artículo 2, reconoce el derecho irrestricto de la constitución de organizaciones sindicales. Ese mismo reconocimiento con la interpretación sesgada ya argumentada — de no aceptar la sindicación para el sector público- esta plasmado en el inciso $1^{\circ}$ y $3^{\circ}$ del Artículo 47 de la Constitución de la República, y en los Artículos 204, 208 al 214 y 248 del Código de Trabajo así como, el Artículo 8 literal b) y 22 literal b) también de la Ley de Organizaciones Funciones del Sector Trabajo y Previsión Social.

Pero a pesar, de que esta reconocido este derecho a la constitución de organizaciones sindicales y a la obligación que tiene el Ministerio de Trabajo y Previsión Social de hacer esta facilitación, abundan casos respecto de la obstrucción de tal derecho.

Existen en El Salvador un total de 129 sindicatos activos, de los cuales 42 de ellos son de industria (32.55\%), 35 de empresa (27.13 $\%$ ), 32 de gremio $(24.81 \%)$, y 20 de trabajadoras y trabajadores independientes $(15.50 \%)$. De este universo se entresacan 11 casos de violación a los derechos laborales y libertades sindicales que se presentan a continuación.

a) Violación al derecho de constitución sindical, reconocido por el Comité de Libertad Sindical de la OIT en el año 2001

Caso SETDESA. El día 22 de noviembre del año 1999, un grupo de trabajadoras y trabajadores miembros de la maquila textil "Doall Enterprises Sociedad Anónima de Capital Variable", ubicada en la zona franca del municipio de San Marcos, 5 kilómetros al sur de la capital, 
conformaron su sindicato de Empresa de Trabajadores Doall Enterprises Sociedad Anónima de Capital Variable (SETDESA).

Esta práctica de conformación de un sindicato en la maquila textil, no fue del agrado de los empleadores coreanos, quienes en respuesta al ejercicio del derecho de sindicación despidieron a todas las y los constituyentes del sindicato, entre ellas a mujeres embarazadas.

Las y los sindicalistas despedidos hicieron del conocimiento del Ministerio de Trabajo y Previsión Social, que eran víctimas de un abuso de su empleador, lo cual estaba claramente señalado en lo que dispone el Art. 205 del Código de Trabajo, que literalmente dice: "Se probibe a toda persona: a) Coaccionar a otra para que ingrese o se retire de un sindicato, salvo el caso de expulsión por causa previamente establecida en los estatutos; b) Impedir al interesado que concurra a la constitución de un sindicato o coaccionar a alguien para que lo baga; c) Hacer discriminaciones entre los trabajadores por razón de sus actividades sindicales o tomar represalias contra ellos por el mismo motivo; $(b)$ Ejecutar actos que tengan por finalidad impedir que se constituya un sindicato o que se encaminen a disolverlo o someterlo a control patronal; $y d$ ) Atentar en cualquier forma contra el ejercicio legítimo del derecho de asociación profesional".

Los funcionarios del Ministerio de Trabajo y Previsión Social en lugar de reparar el daño causado se excusaron de conocer señalando que las y los afectados ya no eran trabajadores de la maquila textil y que por ello no emitía el acto administrativo por medio del cual se tendría que otorgar la personalidad jurídica al sindicato.

La existencia de este doble abuso - de los empresarios coreanos y de los funcionarios del Ministerio de Trabajo y Previsión Social-, llevó a las y los constituyentes de SETDESA a iniciar un peregrinar a largo de 114 días, en los cuales, presentaron escritos ante las Direcciones Generales de Trabajo y de Inspección de Trabajo, ambas instancias del Ministerio de Trabajo y Previsión Social; ante la Procuraduría para la Defensa de los Derechos Humanos; la Asamblea Legislativa; los juzgados de lo laboral; la Corte Suprema de Justicia y ante el Consejo de Administración de la OIT. No de todas las instancia copadas hubo respuesta, para el caso el Ministerio de Trabajo ignoró las solicitudes hechas, y de ello el sindicato tiene el archivo documental que los testifica. 
Al respecto vale acotar con firmeza que el Comité de Libertad Sindical de la OIT emitió una resolución del caso de SETDESA en el informe número 323, caso 285 del año 2001, en lo cual se establece efectivamente en el apartado final de las conclusiones que:"174. En lo que respecta a la queja presentada por el Sindicato de Empresa de trabajadores Doall Enterprises, S.A. de C.V., SETDESA el Comité de Libertad Sindical toma nota de la declaración del Gobierno seguin las cuales el sindicato SETDESA no se le concedió la personería jurídica porque una hora antes de la formación los fundadores del sindicato babian renunciado por escrito a su relación de trabajo; dos que los trabajadores que babian intentado la formación del sindicato fueron reinstalados $y$ posteriormente $y$ pueden si lo desea formar un nuevo sindicato; $y$ tres otros trabajadores formaron el 6 de marzo del año 2000 otro sindicato $y$ se le concedió la personería jurídica. El Comité observa que el gobierno no ba enviado observaciones sobre los alegatos según los cuales la renuncia de los fundadores de SETDESA se habian producido a través de coacciones de representantes de la empresa, para que los trabajadores firmarán bojas en blanco en estas condiciones el Comité estima que no tiene otra elección que concluir que la empresa trato de impedir la constitución del sindicato SETDESA, dado que posteriormente los fundadores pudieran reintegrarse a la empresa y que el gobierno declara que pueden constituir otro sindicato si lo desean. El Comité se limitará a deplorar los actos de discriminación $e$ ingerencia antisindical por parte de la empresa y señalar que los fundadores del sindicato SETDESA que si lo desean puedan realizar unas acciones tendentes a la constitución y reconocimiento a la personeria jurídica del sindicato".

Con esta resolución la OIT valora que se esta violentando el Art. 2 del Convenio 87, y Art. 2 y 3 del convenido 98, respecto la que en la constitución de sindicatos debe haber una protección a las trabajadoras $\mathrm{y}$ trabajadores, de los actos de ingerencia y a ser protegido por organismos nacionales para garantizar el respeto del derecho de sindicación.

Curiosamente también al respecto el Código de Penal de El Salvador, en los Art. 246 y 247 establece lo relativo a acciones penales contra las personas que impidan o discrimen a los trabajadores y trabajadoras por la constitución de un sindicato. A pesar esta resolución, en la que se confirma la vulneración de disposiciones laborales y penales de la normativa salvadoreña, el Ministerio de Trabajo jamás emitió 
ni siquiera una llamada de atención en contra de la empresa Doall Enterprises S.A. de C.V., incumpliendo su función de velar por el respeto de los derechos laborales y de sindicación.

Caso FESTSA. El 4 de marzo del año 2000 se constituyó la Federación Sindical de Trabajadores de Sector Alimento y afines (FESTSA), quienes presentaron la documentación referida por la ley al señor Ministro de Trabajo y Previsión Social, Lic. Jorge Isidoro Nieto Menéndez el 29 de marzo del año 2000.

Con fecha 8 de mayo del año 2000 el Ministro de Trabajo notifico a FESTSA, una resolución que había remitido a las 10 horas y 30 minutos del día 2 de mayo del año 2000 en la cual negaba la personalidad jurídica a FESTSA, aduciendo incumplimiento de formalidades en el acta de constitución.

Ante esta negativa FESTSA recurrió al Consejo de Administración de la OIT a presentar la queja respectiva, la cual fue clasificada como caso 2085.

En junio del año 2001 se tuvo conocimiento de que el Comité de Libertad Sindical llegó a las siguientes conclusiones, a saber: "172. En cuanto a la negativa de concesión personería juridica a la Federación Sindical de Trabajadores del Sector de Alimento y Afines (FESTSA), constituia el 4 de marzo de 2000 integrada por cinco sindicatos, el Comité toma nota de que, según el gobierno, de esta federación no se constituyó dentro de los parámetros legales (Art. 258 y 259 del Código de Trabajo), que presuponen la existencia de convocatorias y actas de cada sindicato (que deben ser examinadas) y que exigen que el notario funcionario competente levante acta de la asamblea fundacional consignando en la misma el nombre, domicilio y clase de cada organización, el número y fecha del acuerdo por el que se otorgó la personalidad jurídica, así como número y tomo del Diario Oficial en que se publicó el asiento registral. El Comité deplora que, dado que se trata de efectos formales fácilmente subsanables, las autoridades no bayan tratado de requerir el complemento de la documentación e información necesario, solicitando a los promotores de la federación que subsanen, en un plazo razonable, las anomalias formales que bubieren advertido en el acta de constitución. El Comité recuerda que si bien es cierto que los fundadores de un sindicato deben de respetar las formalidades previstas por la legislación, a su vez estas formalidades no deben, por su naturaleza, poner trabas a la libre 
creación de las organizaciones (véase recopilación, Op. Cit. Párrafo 248), y pide al gobierno que le tenga informado del curso que en su caso dé a la renovada solicitud de FESTSA con miras a la obtención de su personalidad jurídica”.

Pero la referida federación no solamente requirió ante la OIT el conocimiento de este caso, sino que dado que existen abusos evidentes de parte del Ministerio de Trabajo y Previsión Social, se inició una demanda contra el Ministro de Trabajo, Lic. Jorge Isidoro Nieto Menéndez, ante la Sala de lo Contencioso Administrativo de la Corte Suprema de Justicia, la cual fue presentada el 28 de julio del año 2000 y tiene como referencia 48-F-2000, la referida demanda está en proceso de resolución.

b) Violación al derecho de constitución sindical, sancionado por la Corte Suprema de Justicia de El Salvador

Pero no solamente el Consejo de Administración de la OIT ha señalado la existencia de violación al derecho de constitución sindical en El Salvador de parte del mismo Gobierno; sentencias de la Corte Suprema de Justicia han corroborado que el Ministerio de Trabajo y Previsión Social, en la persona de sus funcionarios son violadores flagrantes de la normativa laboral en detrimento de la libertad sindical en el país.

A continuación se hace una referencia breve a dos casos en los cuales en sentencias firmes de la Corte Suprema de Justicia, se hace constar que el Ministro de Trabajo y Previsión Social es un violador de los derechos sindicales en El Salvador; ordenándosele en la misma que debe restablecer el derecho vulnerado, otorgándole la personalidad jurídica a dos sindicatos que mediante resoluciones amañadas e ilegales del ministerio referido se les impidió por algún tiempo ser sindicatos legalmente reconocidos.

Caso STITHS. E1 24 de marzo de 1998, se constituyó el Sindicato de Trabajadores de la Industria del Turismo, Hostelería y Similares (STITHS). Con fecha 19 de mayo de 1998 se presentó la documentación de constitución ante el Ministerio de Trabajo y Previsión Social. El señor Ministro notificó al STITHS con fecha 1 de julio de 1998 una resolución en la cual se establece que no se otorga la personalidad jurídica en base a dos argumentos: primero, por el hecho de ser un 
sindicato de industria, este debe estar conformado por miembros de diferentes empresas, y el STITHS se constituyó con personas que laboraban en una institución oficial autónoma (el Instituto Salvadoreño del Turismo - ISTU -), y otros de la empresa privada; a consideración del Ministro de Trabajo, aquellas y aquellos que laboran en una autónoma sólo puede constituir sindicatos de empresa, no pudiéndose mezclar empresa privada y autónomas, imposibilitando con ello otorgarle la personalidad jurídica. Una segunda objeción fue argumentar que el turismo no era una industria, entonces no se podía constituir un sindicato de la industria del turismo.

Ante esta negativa, el STITHS presentó una demanda ante la Sala de lo Contencioso Administrativo de la Corte Suprema de Justicia el 10 de julio de 1998, la cual fue codificada con la referencia 84-S-98.

La Sala de lo Contencioso Administrativo emitió una sentencia el día 17 de mayo del año 2000 en la cual se "Falla: a) Declarase ilegal la resolución emitida por el Ministro de Trabajo y Previsión Social, en fecha veintiséis de junio de mil novecientos noventa y ocho, por medio de la cual declaró sin lugar la solicitud de otorgar personalidad jurídica del Sindicato de Trabajadores de la Industria del Turismo, Hostelería y Similares (STITHS); b) Como medida para el restablecimiento del derecho violado, el Ministro de Trabajo y Previsión Social deberá emitir una nueva resolución en que se ordene la inscripción denegada; c) Condénase en costas procesales a la autoridad demandada de conformidad a las reglas del Derecho Comuin; d) En el acto de notificación, entréguesele certificación de esta sentencia a la autoridad demandada y a la representación fiscal; $y$ e) Devuélvase el respectivo expediente administrativo al lugar de origen. NOTIFIQUESE".

El Ministro de Trabajo y Previsión Social, Lic. Jorge Isidoro Nieto Menéndez, notificó al STITHS la resolución en la cual cumplía la sentencia de la Corte Suprema de Justicia, el día veintinueve de mayo del año dos mil dos, 12 días después de que la Corte Suprema había hecho saber su fallo.

El Sindicato de Trabajadores de la Industria del Turismo, Hostelería y Similares (STITHS) tuvo que esperar 26 meses para obtener su personalidad jurídica, por medio de una resolución emitida forzosamente, en cumplimiento a la sentencia de la Corte Suprema de Justicia. 
Caso SUTTEL. Otro ejemplo que ilustra lo atinente a la libertad sindical en el país es el caso del Sindicato de Unidad de Trabajadores de Empresa Compañía de Telecomunicaciones de El Salvador, S. A. de C. V., (SUTTEL), el cual se constituyó el 24 de mayo de 1998, iniciando de inmediato los trámites respectivos ante el Ministerio de Trabajo y Previsión Social, entidad que sin mayor argumentación negó la personalidad jurídica a este sindicato.

Este acto arbitrario condujo a SUTTEL a iniciar un trámite ante la Sala de lo Contencioso Administrativo de la Corte Suprema de Justicia la cual se identificó con la referencia 101-R-98.

La Sala de lo Contencioso Administrativo emitió una sentencia el día 11 de septiembre del año 2000 en la cual se "falla: a) Que es ilegal la resolución emitida por el señor Ministro de Trabajo y Previsión Social a las diez horas y treinta minutos del diecisiete de junio de 1998, por medio de la cual declaro sin lugar la solicitud otorgada de la personalidad juridica a la Asociación Profesional Sindicato de Unidad de Trabajadores de Empresa Compañia de Telecomunicaciones de El Salvador, S. A. de C. V., SUTTEL; b) Como medida para el reestablecimiento del derecho violado, el Ministro de Trabajo y Previsión Social deberá emitir una nueva resolución que conceda la personalidad jurídica denegada y mande a inscribir al sindicato en el registro respectivo; c) Condénese en costas al funcionario demandado de conformidad a las reglas del derecho común; y d) En el acto de notificación, entréguense la certificación de esta sentencia al funcionario demandado y a la representación fiscal. Notifíquese. $Y$ firman los Magistrados de la Sala de lo Contencioso Administrativo de la Corte Suprema de Justicia".

En el caso de SUTTEL, el cumplimiento de la sentencia de la Corte Suprema de Justicia no fue acatada con agrado y prontitud por el Ministerio de Trabajo; tal fue así que el día 18 de septiembre del año $2000-8$ días después de notificada la sentencia a ambas partes- el sindicato requirió mediante un escrito presentado en el despacho del Ministro Nieto Menéndez, la celeridad en la emisión de la resolución en la cual se otorgaría la personalidad jurídica a SUTTEL, en cumplimiento del fallo ya referido.

El 11 de octubre del año 2000, un mes después de notificada la sentencia, SUTTEL presentó a la secretaria de la Sala de lo Contencioso Administrativo un escrito en el cual se hacia saber a los Hono- 
rables Magistrados, que el Ministro de Trabajo se resistía a cumplir el fallo en firme. El 23 de octubre del año 2002, 42 días después de notificada la sentencia y por vía de llamada de atención de los Magistrados de la Corte Suprema de Justicia se emitió la resolución en la cual es mismo Ministro reconoce la ilegalidad cometida y concede la personalidad jurídica a SUTTEL

SUTTEL tuvo que esperar 29 meses para obtener su personalidad jurídica, y todo gracias a ilegalidades que el Ministerio de Trabajo y Previsión Social impuso a un grupo de trabajadoras y trabajadores del sector de las telecomunicaciones. Estos datos irrefutables señalan con certeza la gravedad de las cosas en materia de libertad sindical en El Salvador.

Y el calvario de ilegalidades de SUTTEL no terminó allí, fue hasta el 16 de noviembre del año 2000 cuando se emitieron las credenciales para los directivos sindicales. El sindicato tuvo que esperar 23 días después de emitida la resolución del Ministro Nieto Menéndez, en la cual se otorgaba la personalidad jurídica.

Tres meses después de haberles otorgado las credenciales a los directivos de SUTTEL, el Ministerio de Trabajo emitió una resolución en la cual cancelaba la inscripción de la Junta Directiva, y ordenaba a sus miembros devolvieran las credenciales respectivas, dado que el abogado de la empresa Frace Telecom había impugnado su elección. El apoderado para asuntos laborales de la transnacional France Telecom era un ex Ministro de Trabajo en el Gobierno del ex presidente Cristiani. Con este nuevo abuso del Ministerio de Trabajo, SUTTEL inició en esta ocasión mecanismos de presión con acciones de hecho, los cuales concluyeron el día 8 de marzo del año 2001 , cuando varios cientos de trabajadoras y trabajadores se tomaron la calle en la cual se encuentra el Ministerio de Trabajo, y curiosamente en esas circunstancias se emitieron nuevas credenciales para SUTTEL.

Es difícil cuando no imposible ejercer el derecho de constitución y ejercicio sindical en El Salvador.

c) Violación al derecho de sindicación de las trabajadoras y trabajadores del sector público, reconocido por la OIT

Resulta que una limitante que tiene su origen en la interpretación restrictiva de la Constitución - a la cual ya se hizo referencia con 
anterioridad-, es el argumento que impide el reconocimiento del derecho de organización sindical a las trabajadoras y trabajadores que laboran en el sector público. Este tipo de dificultad ha llevado a que diferentes organizaciones laborales del sector público hagan un esfuerzo por superarles y darle un nuevo giro al ámbito sindical de este sector.

Se hace referencia a dos casos de sindicación en el sector público, y las implicaciones posteriores que ello a traído en el marco legal.

Caso ATRAMEC. El 24 de marzo del año 2000, un grupo de personas que laboran en el Ministerio de Educación conformaron el Sindicato de Trabajadores del Ministerio de Educación (ATRAMEC). Estos presentaron la documentación requerida por la ley al Ministerio de Trabajo y Previsión Social el día 5 de abril del año 2000.

La referida secretaría de Estado notificó una resolución de fecha 4 de mayo del año 2000 en la cual da a conocer al sindicato, en sus considerandos: "... b) Que de conformidad a lo dispuesto en el artículo cuarenta y siete de la Constitución de la República, el derecho a constituir sindicatos pertenece a los trabajadores y patronos privados $y$ de las Instituciones Oficiales Autónomas, principio desarrollado en el Código de Trabajo en el artículo doscientos cuatro, cuando dispone:" Art. 204. Tienen el derecho de asociarse libremente para defender sus intereses económicos y sociales comunes, formando asociaciones profesionales o sindicatos, sin distinción de nacionalidad, sexo, raza, credo, o ideas politicas las siguientes personas: a) Los patronos y trabajadores privados; b) Los trabajadores de Instituciones Autónomas".

Al analizar la documentación presentada en aplicación de las disposiciones legales antes citadas, debe concluirse que las personas que aparecen listadas como constituyentes del sindicato, no tienen el derecho de formar sindicatos, puesto que al ser empleados del Ministerio de Educación, que es un agente público, adquieren la categoría de empleados públicos, como bien lo reconocen los mismos constituyentes en el acta notarial antes relacionada, siendo en consecuencia improcedente la petición de los fundadores y realizar el trámite indicado en el artículo doscientos diecinueve del Código de Trabajo, cuando por ley esta probibida la constitución de sindicatos con empleados públicos, y que en el articulo 2 del mismo código, se establece que las disposiciones del mismo cuerpo legal no son aplicables a los empleados públicos. 
Por tanto, con base en lo antes expuesto y a las disposiciones legales citadas, este despacbo RESUELVE: SIN LUGAR la aprobación de los estatutos y la concesión de la personalidad jurídica solicitada para el Sindicato de Trabajadores del Ministerio de Educación por estar constituido en contravención a la Constitución de la República y al Código de Trabajo vigente. Comuníquese, J. Nieto. M.”.

Ante esta resolución en la cual evidentemente se niega el derecho de sindicación para las trabajadoras y trabajadores del sector público, ATRAMEC presentó un recurso de revocatoria ante el mismo despacho ministerial, el día 5 de mayo del año 2000. La conducta del Ministro de Trabajo fue ignorar el recurso interpuesto, $y$ no fue sino hasta el 9 de agosto del año 2000, cuando denegó sin argumentación alguna el recurso de revocatoria del acto administrativo; 96 días después de su interposición, cuando la ley le da el plazo de 5 días para responder, y tan es así que a sabiendas de ello, la fecha de la resolución fue 8 de mayo del 2000. Este acto fue interpretado por el Sindicato como una falta de respeto de parte del Ministro de Trabajo y Previsión Social.

El 5 de junio del año 2000 ATRAMEC presentó una queja ante el Consejo de Administración de la OIT la cual fue clasificada por el Comité de Libertad Sindical como caso número 2085. Esta instancia emitió la resolución por medio del informe número 323 del mes de junio del año 2001, y respecto de este caso, el Comité de Libertad Sindical en su oportunidad resolvió: "173. En cuanto a la negativa de personalidad jurídica al Sindicato de Trabajadores del Ministerio de Educación (ATRAMEC) en mayo de 2000, el Comité toma nota de que, según el gobierno, la Constitución de la República permite el derecho y asociación a los trabajadores del sector privado y a los de las Instituciones Oficiales Autónomas, pero no pueden bacer uso de ese derecho los trabajadores al servicio del Estado (Empleados Públicos o Empleados de Gobierno), ya que el Estado ofrece servicios esenciales que no pueden ser interrumpidos bajo ningún concepto. El Comité debe subrayar a este respecto que LA DENEGACIÓN DEL DERECHO DE SINDICACIÓN A LOS TRABAJADORES AL SERVICIO DEL ESTADO CONSTITUYEN UNA GRAVÍSIMA VIOLACIÓN A LOS PRINCIPIOS MÁS ELEMENTALES DE LA LIBERTAD SINDICAL. EN CONSECUENCIA, EL COMITÉ INSTA AL GOBIERNO A QUE VELE PORQUE CON CARÁCTER URGENTE SE ENMIENDE LA LEGISLACIÓN NACIONAL DE EL SALVADOR PARA QUE 
RECONOZCA EL DERECHO DE SINDICACIÓN A LOS TRABAJADORES AL SERVICIO DEL ESTADO, con la única posible excepción de la Fuerza Armada y Policía". A esta consideración se suma en el apartado de las recomendaciones del mismo pronunciamiento el Comité de Libertad Sindical hace una reiteración firme: "Recomendaciones del Comité: ... b) El Comité insta al gobierno a que vele porque, con carácter urgente, se enmiende la Legislación Nacional de El Salvador a efectos de que se reconozca el derecho de sindicación de los trabajadores al servicio del Estado con la única posible excepción de la Fuerza Armada y Policia."

Con fecha 10 de octubre del año 2001, el Secretario General del Sindicato de Trabajadores del Ministerio de Educación (ATRAMEC), envió una nota al despacho del señor Ministro de Trabajo y Previsión Social, a la cual le adjuntaba copia de la resolución del Comité de Libertad Sindical, y se solicitaba se cumpliese con lo allí resuelto. Una vez más la actitud del Ministro Nieto Menéndez fue ignorar tal solicitud y no ha enviado hasta la fecha contestación alguna.

Este escenario condujo a ATRAMEC, a hacer del conocimiento de la OIT que el Gobierno de El Salvador no ha acatado las recomendaciones ya apuntadas. El 2 de abril del año 2002, el Jefe del Departamento de Libertad Sindical de la OIT, Bernard Gernigon envió nota a ATRAMEC en la cual notifica al sindicato que es conocedor de las circunstancias referidas en la queja, y reabre el expediente a favor de la libertad sindical en el sector público de El Salvador, bajo el número 2190.

Pero el Sindicato de Trabajadores del Ministerio de Educación (ATRAMEC) no sólo se ha quedado ante la instancia de la OIT, quien sabiamente estableció la existencia de la violación del derecho a la libertad sindical en El Salvador para las trabajadoras y trabajadores del sector público, sino que a demás presentó el 25 de julio del año 2000 una demanda de amparo en contra el Ministro de Trabajo y Previsión Social ante la Sala de lo Constitucional de la Corte Suprema de Justicia, la cual se identifica con la referencia 434-2000. Dicho proceso está pendiente de sentencia.

A esta altura con la resolución favorable de la OIT, la reapertura del expediente y el fallo pendiente de la Corte Suprema de Justicia, el Sindicato de Trabajadores del Ministerio de Educación (ATRAMEC) 
se esta preparando para arribar a una nueva instancia: la Comisión Interamericana de Derechos Humanos.

La ratificación de los Convenios 98,87 y para este caso en particular el 151 de la OIT, bien vale estos esfuerzos.

Caso SITRAMH. Pero, el caso de ATRAMEC no es un caso aislado, hay varios al respecto en El Salvador, uno de ellos es el que a continuación se presenta.

El 1 de mayo del año 2001, un grupo de trabajadoras y trabajadores del Ministerio de Hacienda se reunieron para constituir el Sindicato de Trabajadores del Ministerio de Hacienda (SITRAMH). La documentación que exige la ley fue presentada al Ministerio de Trabajo el 15 de mayo del año 2001.

Como era de esperar el 26 de junio del año 2001 el referido Ministerio notificó al SITRAMH la negativa para poder otorgarles la personalidad jurídica. Curiosamente, la resolución notificada adolecía de una serie de errores entre ellos que la fecha de emisión del acto administrativo de la resolución notificada era el 21 de mayo del año 2000, cuando a esa fecha no se había constituido el sindicato; se nominaba equivocadamente al Notario, y se hacían una serie de aseveraciones, que resultaban ser incoherentes con el caso que se atendía, al parecer estos datos fueron tomados de un esquema de otra notificación.

Ante esta curiosa notificación, se presentó un recurso de revocatoria el día 27 de junio del año 2001 haciendo las acotaciones respectivas; el mismo día el Ministerio de Trabajo volvió ha notificar la negativa de otorgar la personalidad jurídica.

A esta altura hay que hacer notar que el artículo 219 del Código de Trabajo establece que la personalidad jurídica de un sindicato se puede otorgar por dos vías: la primera, por la emisión de un acto administrativo en el cual se resuelve otorgar la personalidad jurídica a la organización solicitante; y el segundo, vía silencio administrativo, es decir cuando el Ministerio de Trabajo guarda silencio a lo largo de 30 días hábiles - término contabilizado a partir de la fecha de presentación de la documentación inicial de parte del sindicato-, entonces se entenderá que esta otorgada la personalidad jurídica a favor de este.

Resulta que esta segunda notificación de la negativa de otorgar la personalidad jurídica a SITRAMH fue notificada el día 27 del mes de 
junio del año 2001, este era el día hábil 31 dentro de la contabilidad procesal ya explicaba; en tal razón con fecha 6 de julio del año 2001, el sindicato pidió al Ministro de Trabajo que emitiese una constancia del silencio administrativo, vía por la cual se estaba otorgando la personalidad jurídica al sindicato.

Ante esta solicitud, el Ministro Menéndez estableció en una resolución notificada el día 9 de julio del año 2001, aspectos que contrarían lo relativo a la Ley de Organización y Funciones del Sector Trabajo y Previsión Social y al Código de Trabajo.

Los hechos ya referidos condujeron al Sindicato de Trabajadores del Ministerio de Hacienda (SITRAMH) a presentar una demanda el día 4 de octubre del año 2001, ante la Sala de lo Contencioso Administrativo de la Corte Suprema de Justicia, esta se identifica con la referencia 132-S-2001, la cual tiene como autoridad demandada al Ministro de Trabajo y Previsión Social por la emisión de una resolución en contra del derecho.

\section{d) De la violación del ejercicio de los Directivos Sindicales}

Los casos hasta aquí referidos, relativos a la libertad de sindical, se circunscriben a comprobar como se violenta o no se facilita los mecanismos necesarios para la constitución de sindicatos y su legal ejercicio. Esta realidad institucionalizada, a conducido a las organizaciones laborales a recurrir a instancias internacionales como la OIT y la Corte Suprema de Justicia, las cuales han ratificado las pretensiones y reivindicaciones a favor de la libertad sindical.

Pero en El Salvador no son los casos de obstrucción de la constitución sindical los que exclusivamente agobian a las organizaciones laborales, sino además existe un marcado entorpecimiento al desarrollo de las labores de Directivos Sindicales. El convenio 98 de la OIT en los Art. 2 y 3 señalan la obligación de los Estados de generar las políticas necesarias que permitan ejercer una protección ante los actos de ingerencia de la Constitución y Funcionamiento y Administración Sindical.

Esta disposición legal de la OIT esta respalda por lo que dispone el Artículo 47 inciso $4^{\circ}$ de la Constitución, los Art. 248, 249, 250 y 205 del Código de Trabajo, y 246, 247 del Código Penal, en los cuales establece un grado de protección: llámese fuero sindical o prohibición 
de actos de ingerencia o discriminación por calidad de Directivos Sindicales.

Existen en la práctica salvadoreña casos que han contrariado las disposiciones legales citadas, y que no se hable por el momento de las disposiciones de la OIT, las cuales el gobierno salvadoreño con una actitud de poca apertura y desinterés por desarrollo del Derecho Internacional del Trabajo en el país se ha negado a ratificar, basta la referencia al incumplimiento de la norma nacional y valga al respecto citar un par de casos.

Caso de directivos de STSEL. El apoderado legal de la institución oficial autónoma nominada Comisión Ejecutiva Hidroeléctrica del Río Lempa (CEL), una de las principales generadoras de energía eléctrica en el país, presentó el día 30 de agosto del 2001, un escrito ante el Departamento Nacional de Organizaciones Sociales en el cual impugnaba en nombre de la CEL la calidad de directivo sindical del Secretario de Finanzas de la Seccional CEL del Sindicato de Trabajador del Sector Eléctrico (STSEL).

El sindicato respondió ante esta solicitud el día 11 de septiembre del año 2001, argumentando abundantemente las razones legales de lo improcedente que era que la empresa pudiese realizar trámites que concluyesen en la pérdida de la calidad de directivo sindical, todo con el aval del Ministerio de Trabajo. El número de expediente que implicó el proceso de impugnación de la calidad de Directivo Sindical fue el 19-2001 LC a cargo del Departamento Nacional de Organizaciones Sociales.

El Ministerio de Trabajo y Previsión Social emitió el 21 de septiembre una resolución en la cual se retiraba la calidad de directivo sindical al Secretario de Finanzas referido. Esta resolución llevó la complicidad de acciones de inspección instruidas a solicitud de la CEL y ejecutadas por orden del Director General de Inspección de Trabajo. En el proceso de impugnación realizada por el sindicato el 21 de septiembre del año 2001, se solicitó al Director General de Inspección tener acceso al expediente respectivo, dado que como parte afectada se pretendía tener la información necesaria para hacer una mejor defensa. Ante esta solicitud, y en contra de toda lógica procesal, el Director General de Inspección, señaló que los expedientes de inspección eran confidenciales, y que no se podía emitir certificación alguna,

\section{8}

Realidad 93, 2003 
ni permitir acceso de los mismos. Pero los abusos no concluyeron allí; luego que el Ministerio de Trabajo retirarle la calidad de directivo sindical al secretario de finanzas, el paso siguiente de la CEL fue despedirle de su trabajo.

Estos hechos no podían quedar en la impunidad, y el sindicato inició un proceso ante la Sala de lo Contencioso Administrativo de la Corte Suprema de Justicia. El 8 de octubre del año 2001 se presentó la demanda en contra del Director General de Inspección de Trabajo y del Jefe del Departamento Nacional de Organizaciones Sociales, proceso identificado con el número de referencia 115-C-2001.

La Corte Suprema de Justicia del simple estudio de la demanda y de los alegatos iniciales el día 7 de noviembre del año 2001 ordenó al Ministerio de Trabajo y Previsión Social la suspensión provisional de la ejecución de los actos administrativos impugnados es decir, ordenó al Jefe del Departamento Nacional de Organizaciones Sociales que devolviese la credencial al Directivo Sindical ya referido, hecho con el cual se confirmaba de entrada que efectivamente una vez más el Ministerio de Trabajo había actuado en la ilegalidad.

La Corte Suprema de Justicia abrió el término de prueba del referido proceso, el día 27 de noviembre del año 2001. El Ministerio de Trabajo a través de los dos funcionarios demandados presentó una prueba en la cual fue catalogada por la Corte como incoherente. En una resolución notificada el 22 de febrero del año 2002 se ordenó multar a los funcionarios del Ministerio de Trabajo y se llamó la atención respecto de la prueba presentada.

A la fecha se espera con altas expectativas a favor del sindicato, la sentencia de la Sala de lo Contencioso Administrativo de la Corte Suprema de Justicia, en la cual una vez más se señale que el Ministerio de Trabajo viola los derechos sindicales.

Este no fue el único caso que ha afectado a los directivos de STSEL en el último año. Entre septiembre del año 2001 a junio del año 2002 han sido despedidos un total de 12 Directivos Sindicales de Juntas Directivas Seccionales y General de STSEL. Esto a pesar de la protección legal que esta respaldada en las disposiciones ya citadas, y al hecho que en todas la seccionales de STSEL existe contrato colectivo de trabajo. Por cada uno de estos despidos se siguen acciones sindicales de naturaleza legal y de hecho. 
Caso de militarización del aeropuerto y despido de directivos de SITEIAES. El 24 de septiembre del año 2001, el Gobierno de El Salvador ordenó militarizar el Aeropuerto Internacional de El Salvador, hecho en el cual participó un contingente de agentes de la Policía Nacional Civil (PNC), efectivos de las fuerzas especiales de la Fuerza Aérea, miembros del ejército, entre otros ${ }^{* 13}$.

Paralelo a la militarización del aeropuerto, la Comisión Ejecutiva Portuaria Autónoma (CEPA), autónoma que tiene bajo su responsabilidad la administración del Aeropuerto Internacional El Salvador, ordenó suspender los contratos individuales de trabajo y posteriormente despedir a más de 200 trabajadores, adscritos a las áreas de carga y vigilancia del referido puerto aéreo. Entre los despedidos se encontraban 4 directivos sindicales.

A este contingente de trabajadores no se les devolvió su empleo, se quedaron fuera de la empresa por una simple decisión de parte del Gobierno de El Salvador. El Sindicato de Trabajadores por Establecimiento del Aeropuerto Internacional El Salvador (SITEAIES) presentó una queja ante la Procuraduría para la Defensa de los Derechos Humanos, la cual resolvió que había existido una violación a los derechos laborales y sindicales de parte de CEPA, el Ministerio de Trabajo y de la Presidencia de la República. A pesar de esta resolución, las autoridades del órgano ejecutivo no hicieron cambio alguno en su práctica ilegal y violatoria de la Ley Laboral.

SITEAIES presentó también ante la OIT una queja denunciando el despido de directivos sindicales y afiliados al sindicato lo que ha implicado que el Sindicato haya quedado minimizado a consecuencia del proceso de militarización. Aun no existe respuesta de la OIT al respecto.

\section{e) De la violación a la existencia de la contratación colectiva}

Este mismo escenario ya citado para los casos de los sindicatos y de algunos directivos sindicales esta considerado también en el ámbito de la contratación colectiva. Solamente en el año 2002 a consecuencia de haber procurado intentos de negociación colectiva, estos han concluido con la desaparición de los sindicatos promotores.

Caso SIPES. El Sindicato de la Industria Portuaria de El Salvador (SIPES), inició un proceso de negociación colectiva, en la cual se tenía 
como contraparte la Comisión Ejecutiva Portuaria Autónoma (CEPA). Luego de agotar las etapas de trato directo y conciliación, en la cual se alcanzó el acuerdo de buena parte del contrato; CEPA y SIPES sometieron al proceso de arbitraje un número reducido de cláusulas, debiendo el tribunal arbitral remitirse exclusivamente a ese ámbito. A pesar de ello en el laudo arbitral pronunciado, se modificaron no solo las cláusulas en las cuales no hubo acuerdo, sino en otras más. Ello fue un acto ilegal y arbitrario de los miembros del tribunal arbitral, acción que fue acompañada con la inscripción del mismo en el registro respectivo del Ministerio de Trabajo y Previsión Social.

Esto vino a redundar en el hecho del despido de todos los trabajadores de CEPA y el desaparecimiento del Contrato Colectivo y del mismo sindicato ${ }^{* 14}$.

Caso SELSA. Iguales hechos ocurrieron respecto del Sindicato Empresa Lido Sociedad Anónima (SELSA) ${ }^{* 15}$ con la Empresa Lido, S. A. una empresa de panificación que existe en el país, propiedad de la familia Molina.

SELSA inició el conflicto colectivo de carácter económico o de intereses, el cual procesalmente conduce a la negociación colectiva. Luego de agotar el trato directo, en la etapa de la conciliación sucedió una ruptura en el proceso, esto llevó a SELSA a iniciar acciones de hecho, como medidas de presión para hacer avanzar las diligencias. Al pretender un acercamiento con la empresa LIDO S.A. la respuesta fue el despido de 51 trabajadoras y trabajadores entre ellos los miembros de la Junta Directiva quienes vienen peregrinando desde inicios de mayo del 2002, sin ninguna respuesta ni alternativa que pudiese ofrecerles el Ministerio de Trabajo o los Tribunales.

Caso STITHS. La seccional del Instituto Salvadoreño de Turismo (ISTU), del Sindicato de Trabajadores de la Industria del Turismo, Hostelería y Similares (STITHS), inició los trámites para la celebración del proceso de negociación colectiva ante la Dirección General de Trabajo del Ministerio de Trabajo el día 21 de agosto del año 2000.

El día 11 de septiembre del año 2000, el Ministerio de Trabajo y Previsión Social admitió la solicitud hecha por el STITHS, y notificó de ello a su contraparte, el ISTU. El día siguiente 12 de septiembre, sucedió la primera reunión entre los delegados del sindicato y del ISTU en la negociación, logrando un acuerdo en el calendario de re- 
uniones y procedimiento del mismo. A lo largo de 8 meses y medio, se negoció el referido contrato, llegando en medio de discusiones tensas a un documento final. Pero a esa altura el calvario apenas iniciaba.

El Código de Trabajo señala en su Art. 287, que "Todo contrato celebrado con una institución oficial autónoma, necesita para su validez la aprobación del respectivo Ministerio, oyendo previamente la opinión del Ministerio de Hacienda.

La institución oficial autónoma que celebre dicho contrato, estará obligada a comunicar el texto del mismo a la Corte de Cuentas de la República". En base a lo anterior, al finalizar la negociación colectiva, el documento consensado paso al Ministerio de Economía el 17 de julio del 2001, el referido despacho lo examino a lo largo de 13 días y le dio su aprobación, enviándole al Ministerio de Hacienda el 22 de agosto del año 2001, fecha en la que se "celebraba" el primer aniversario de que el Ministerio de Trabajo y Previsión Social había recibido los documentos del STITH para iniciar la negociación colectiva. Desde la referida fecha - más de un año- se encuentra el documento de contrato colectivo del STITHS en el despacho del Ministro de Hacienda, siendo imposible su inscripción y valides, a favor de las trabajadoras y trabajadores. Al 31 de agosto del 2002, el proceso de negociación colectiva iniciado por el STITHS y inscripción del documento respectivo lleva 739 días y sumando.

Triste escenario el de la negociación colectiva salvadoreña. Los casos citados son solo una muestra, dentro de sobreabundancia que existen.

\section{Retos pendientes, una manera de concluir}

Después de concluir una jornada de estudio, sistematización, entrevistas e investigación, que están reflejadas y plasmadas en este breve ensayo, se consideró oportuno proponer para el debate tres conclusiones, que están redactadas más bien a manera de retos pendientes a asumir como sociedad salvadoreña y como sectores vinculados al tema laboral.

- Rescate de la institucionalidad del Ministerio de Trabajo y Previsión Social 
En este breve ensayo se ha ido comprobando, con dados que pueden ser fácilmente cotejados, que uno de los principales violadores de los derechos laborales y libertades sindicales en El Salvador es el Ministerio de Trabajo y Previsión Social, en la persona de sus funcionarios, directores generales e inspectores -entre otros-, al incumplir las facultades que contempla la ley, o con el simple acometimiento de ilegalidades. De esta afirmación no debe deducirse que en el país no existen empresarios que también violentan estas áreas laborales y sindicales, por supuesto que las hay, y aquí se han hecho referencia a algunos de ellos - y en algunos sectores como la maquila textil existe un énfasis mayúsculo-. Esta afirmación puede ser respaldada con una sobreabundancia de datos.

El énfasis en el Ministerio de Trabajo y Previsión Social tiene una intencionalidad clara: la preocupación y gravedad que en un país que dice tener vocación democrática e interés por marchar en la senda de la instauración del Estado de Derecho, resulta que el ente público que tiene la obligación de velar por el respeto de los derechos laborales y libertades sindicales es un reiterado violador o cómplice de ilegalidades, así lo confirman fallos emanados de la Corte Suprema de Justicia, resoluciones de la procuraduría para la Defensa de los Derechos $\mathrm{Hu}$ manos, y recomendación de entes internacionales como la OIT.

De estas acotaciones resulta lógica la primera conclusión: es impostergable la recuperación de la institucionalidad del Ministerio de Trabajo y Previsión Social, esto pasa por adoptar una gama de medidas, que solo con afán de iniciar el debate se pueden apuntar:

a) Iniciar un proceso de evaluación exhaustiva del personal del Ministerio de Trabajo y Previsión Social, a fin de que su personal este compuesto por personas conocedoras de la materia y con un perfil incorruptible;

b) Teniendo como base tal evaluación, sus resultados necesariamente deben conducir a una depuración de personal, sobre todo en la Dirección General de Inspección de Trabajo, quienes están seriamente cuestionados por prácticas de corrupción;

c) Que las trabajadoras, trabajadores y sus organizaciones laborales sean supervisores del desempeño del personal del Ministerio de Trabajo y Previsión Social, y demanden ante las instancias perti- 
nentes las ilegalidades, venalidades y abusos que se cometan. La cultura de la denuncia de estos hechos debe ser una práctica que debe acentuarse, dado que dejar pasar los hechos sin la denuncia respectiva, vuelve a las víctimas en cómplices del estado de las cosas;

d) El Ministro y Viceministro deben facilitar el acceso de las personas y organizaciones, con la finalidad de conocer de primera mano sus posturas, críticas, acciones y propuestas. La labor de liderear esta cartera de estado requiere de una práctica de concertación y diálogo permanente;

e) Debe adoptarse al interior del Ministerio de Trabajo y Previsión Social, métodos que permitan una mayor agilidad en la atención. La conciliación y el arbitraje son mal usados en la atención a los problemas laborales, la falta de capacitación o el desinterés por el trabajo ha llevado a que algunos de los resolutores les practiquen con desgano y displicencia;

f) Estas propuestas pasan por un rol más protagónico de las instancias tripartitas, que desarrollen sus propuestas más de cara a la opinión pública, a fin de que su labor cuente con el aval o la crítica de los sectores a quienes se dice representan (trabajadoras/trabajadores, empleadoras/empleadores, funcionarios públicos);

g) El Ministerio de Trabajo requiere de mayor presupuesto, las asignaciones que se le hacen son ínfimas respecto de los retos que enfrenta;

\section{- Rescate de la institucionalidad del movimiento sindical}

Otro de los ámbitos que requieren de una profunda atención y cambio es el movimiento sindical salvadoreño.

En la práctica de ilegalidad e irrespeto de los derechos laborales y libertades sindicales que existe, el movimiento sindical tiene sin duda alguna responsabilidad. La pérdida de fuerza organizativa; la ausencia de propuesta e iniciativa para contrarrestar los cambios que genera de empresa privada y el gobierno desde su modelo neoliberal; la corrupción y venalidad de algunos dirigentes sindicales, que son cómplices del status quo; la no existencia de participación significativa de la mujer; la ausencia de nuevos cuadros sindicales que procuren el necesario 
relevo generacional; el desconocimiento de los procedimientos e instancias legales a las que puede recurrirse para defender sus derechos; la comodidad de muchos; la ausencia de espacios reales de diálogo entre las afiliadas y afiliados sindicales y sus dirigencias; entre otros resultan ser manifestaciones de esta crisis que está llevando a la desaparición del movimiento sindical.

Esta realidad, que también se puede comprobar con datos y hechos accesibles, requiere de una particular atención, de nuevo a manera de propuesta se plantean un par de ideas que pudiesen servir a aquellas y aquellos que están interesados de verdad en que el movimiento sindical resurja:

a) Crear mecanismos operativos que permitan tener certeza respecto de cuántos sindicatos, afiliadas y afiliados efectivamente existen, dado que la tendencia de algunos dirigentes es inflar las cifras, falacia que les garantiza mayores cuotas de poder en las instancias tripartitas;

b) Teniendo claridad del estado numérico del movimiento sindical, se debe hacer un diagnóstico de su condición actual, señalando sin tapujos sus capacidades, crisis crónicas, y proyecciones. Este diagnóstico debe servir para tomar decisiones de cambio;

c) Las organizaciones sindicales deben invertir más en procesos de formación, en la generación de nuevos cuadros sindicales;

d) Los sindicatos deben replantearse sus métodos de organización, los espacios de comunicación entre las afiliadas, afiliados y sus representantes;

e) Debe hacerse énfasis en las dirigencias del movimiento sindical salvadoreño, en el fortalecimiento del aspecto ético combatiendo frontalmente y depurando a su interior acciones que no deben ser toleradas como la corrupción, el acoso sexual, la no rendición de cuentas, entre otros;

f) El movimiento sindical debe tener una labor de sistematización de la realidad laboral y sindical en el país, con la finalidad de realizar una labor contralora de la legalidad laboral;

g) Debe capacitarse equipos de gestión legal al interior de los sindicatos, con la finalidad de que se utilicen de manera adecuada y pronta 
las instancias en las cuales se denuncien las ilegalidades que se constaten;

h) La adopción de una política de contacto permanente con la población debe ser privilegiada. En estos tiempos el movimiento sindical debe ser un ente que no sólo privilegie la defensa de sus intereses laborales, sino que vigile y defienda los intereses de las y los consumidores de sus productos y servicios. La presencia en los institutos nacionales, presentando a las y los estudiantes el planteamiento legal de lo que es un sindicato y sus beneficios, podría ayudar a sensibilizar a estos sectores que son los que en el corto plazo engrosaran la filas de empleados o desempleados;

i) Finalmente debe procurarse una política de contacto con los medios de comunicación y una generación de opinión pública. No existe en el marco comunicacional salvadoreño, un referente sindical.

\section{- Readecuación y desarrollo del marco legal laboral}

Finalmente -y no porque con ello se agota la gama de propuestas- un ámbito que debe ser revisado es la readecuación y desarrollo del marco legal laboral, encaminado a preservar fundamentalmente la función tuitiva del derecho laboral. Se hace énfasis en la intención del cambio legal, dado que en el marco de la flexibilización laboral, uno de los ejes de operativización pasa por desregular las relaciones laborales; es decir desaparecer o minimizar las reglas del juego que van a regir las relaciones laborales, a tal grado que sean las reglas del mercado las que funjan.

En tal dirección los empresarios, Ministro de Trabajo Previsión Social y legisladores miembros del partido en el gobierno, han hecho una serie de propuestas encaminadas en tal dirección, valga mencionar rápidamente algunas de ellas: el proyecto de "Ley Especial de Reactivación del Empleo" (LERE) en la cual se proponía modificar completamente en régimen del contrato individual de trabajo; el proyecto le "Ley de Formación Profesional", la cual requiere de una reforma constitucional del Art. $41 \mathrm{Cn}$., y de aprobarse desaparecería todo el capítulo del Código de Trabajo referido a aprendices (Art. 61 al 70 Código de Trabajo); la propuesta de la Asociación Salvadoreña de la Industria de la Confección (ASIC) de establecer el salario míni- 
mo a 700.00 en las maquilas que se establezcan en las zonas francas del interior del país, bajo el argumento que con ello se les ahorraría pasajes, comida y otros gastos; y finalmente la negativa de ratificar convenios fundamentales de la OIT, como los relativos a la libertad sindical.

Esta propuesta va en sentido completamente opuesto, deben generarse medidas que se encaminen a construir cambios legales que procuren una mayor y mejor defensa de los derechos laborales y libertades sindicales. Este aspecto sin duda se encuentra con el escollo de "la aritmética legislativa" necesaria para lograr los votos que respalden la propuesta, pero aún en tales casos el movimiento sindical pudiese considerar:

a) Aglutinar esfuerzos organizativos que respondan a problemas sentidos por la población, y a partir de allí construir propuestas legales que se encaminen a las reformas legales, un buen ejemplo actual de esta afirmación es el descontento por los ya sentidos efectos del Sistema de Ahorros para Pensiones, que van sumando al sector magisterial, pensionados, médicos, entre otros;

b) Hacer un estudio exhaustivo de toda la normativa laboral a fin de ir construyendo propuestas de reforma, que se encaminen a la defensa de los derechos laborales, y al cambio radical de los procedimientos administrativos y jurisdiccionales en materia laboral;

c) Realizar informes paralelos, justificados y suficientemente respaldados, de la aplicabilidad o violación de los Convenios de la OIT ratificados, de Pactos Internacionales, y hacerlos llegar a las instancia pertinentes;

d) Establecer un contacto permanente con el Departamento de Derecho Laboral de la Procuraduría General de la República, y con la Procuraduría Adjunta de los Derechos Laborales de la Procuraduría para la Defensa de los Derechos Humanos, a fin de procurar capacitaciones, conocimiento de criterios legales aplicables, intercambio de información que pueda ser de interés común;

e) Participación directa y protagónica de los dirigentes sindicales en los procedimientos administrativos - Ministerio de Trabajo y Previsión Social- y jurisdiccionales - tribunales de diferentes instancias-, que procuren la defensa de los derechos laborales y libertades sindicales de sus afiliados; 
f) Contacto y cabildeo permanente de los dirigentes sindicales con las diputadas y diputados de la Asamblea Legislativa, de todas las fracciones partidarias, que atienden los temas vinculados con su sector laboral, a fin de hacerles sentir sus pretensiones;

g) Establecer una política de relación y diálogo con los Jueces de Primera Instancia y Cámaras de lo Laboral, a fin de conocer sus criterios de acción legal, y ejercer la necesaria presentación de los criterios sindicales;

h) La relación con las Federaciones de Abogados, y con las escuelas de derecho de las Universidades de mayor prestigio pudiese ser estratégicamente bien utilizada.

El trabajo por hacer es arduo, y emprenderlo demanda como condiciones fundamentales al menos tres pilares: el compromiso por el cambio a favor de la clase trabajadora; descartar el espacio a la desesperanza; y procurar procesos de discernimiento colectivo que conduzcan a la toma de decisiones que efectivamente se le va a dar marcha.

La existencia y desarrollo del sindicalismo en El Salvador, es una necesidad para el avance de la democracia y de los procesos de maduración política. El sector empresarial y los funcionarios del gobierno deben comprender que un país no se construye teniendo como premisa la exclusión, o la desaparición de la contraparte para imponer mi visión; esa fórmula ya se intentó en las décadas 60-70 del siglo pasado y provocó violencia; insistir en la misma dirección sería equivalente a reconocer la terquedad de no aprender las lecciones de la historia.

La siembra de la semilla de la exclusión trae consigo el cultivo floreciente de la violencia. Este no es el camino que las salvadoreñas y salvadoreños queremos para nuestras hijas e hijos. De allí que es impostergable empezar la marcha para un cambio, de no hacerlo los, mismos sindicalistas serán corresponsables del descalabro del ya débil marco legal existente. Es tiempo de "ser astutos como serpientes y sencillos como palomas" para realizar una labor que efectivamente alcance una conversión firme y sostenida.

\section{Notas}

1. El autor es abogado laboralista y apoderado de organizaciones sindicales en El Salvador. El presente artículo fue elaborado para animar el debate en una jornada auspiciada por la OIT en septiembre del año 2002, en la cual participaron las 
principales centrales obreras de El Salvador, relativa a una evaluación de la normativa laboral en los principales aspectos del marco laboral.

2. Cfr. "Dr. Armando Calderón Sol. Discurso de toma de posesión”. Publicación en Revista Estudios Centroamericanos, ECA No. 547 - 548; meses de mayo junio de 1994. UCA Editores, San Salvador, Pág. 603.

3. Cfr. Acta de Constitución de la OIT, 1919

4. Cfr. "Ley de Accidentes del Trabajo", emitido por la Asamblea Nacional Legislativa el 12 de mayo de 1911, y publicada en el Diario Oficial No. 109, Tomo No. 70, Pág. 1165-1166 del 13 de mayo de 1911. Dicha normativa sufrió, antes de su derogatoria, cuatro reformas en los años de 1916, 1941, 1942 y 1948.

5. Cfr. "Ley de Registro de Agrupaciones Obreras y Gremiales". emitido por la Asamblea General Legislativa el 28 de octubre de 1927.

6. Cfr. "Ley General sobre Conflictos Colectivos de Trabajo", Decreto No. 322 emitido por la Asamblea Nacional Legislativa el 12 de enero de 1946, y publicado en el Diario Oficial No. 11, Tomo No. 140, Pág. 100-102, del martes 15 de enero de 1946.

7. Cfr. "Decreto Legislativo que creó el Ministerio de Trabajo y Previsión Social". Decreto No. 134, emitido por la Asamblea Nacional Legislativa el 14 de octubre de 1946. publicado en el Diario Oficial No. 234, Tomo No. 141, Pág. 3389-3390, del martes 22 de octubre de 1946.

8. Respecto del ofrecimiento de empleos, hay que acotar que uno de los rasgos característicos del ámbito laboral salvadoreño es la precarización del empleo, al respecto se pueden consultar datos emanados de notas periodísticas: "Según datos del INSAFORP Déficit de 70 mil empleos cada año". La Prensa Gráfica del día lunes 11 de febrero del 2002, Pág. 44.

9. Se puede consultar la siguiente nota periodística, que está vinculada con este aspecto: "INSAFORP capacitará a más de $11 \mathrm{mil}$ jóvenes. La apuesta por aprender un oficio". El Diario de Hoy del día lunes 27 de mayo del 2002, Pág. 17.

10. Se puede consultar las siguientes notas periodísticas, que están vinculadas con estos aspectos: "En El Salvador más de 159 mil niños entre 10 y 17 años se dedican a trabajar. $\$ 7$ millones para erradicar trabajo infantil". La Prensa Gräfica del día jueves 28 de junio del 2001, Pág. 24. "Niños que trabajan: Grandes problemas y mínimas soluciones". CoLatino del día lunes 27 de mayo del 2002. Pág. 4. "El Código de la Niñez probibirá el trabajo a menores de 12 años". La Prensa Gráfica del día jueves 30 de mayo del 2002, Pág. 18. "Día mundial contra el trabajo infantil. 56 mil niños se suman a trabajo infantil". La Prensa Gráfica del día miércoles 12 de junio del 2002, Pág. 4 y 5. "Para aportar a la economía familiar niños realizan trabajo peligroso". El Diario de Hoy del día miércoles 12 de junio del 2002, Pág. 14.

11. Se puede consultar Cardona Monterrosa, Amílcar Efrén. "Estado de las organizaciones de trabajadoras y trabajadores del Sector Público". Publicación del Centro de Estudios del Trabajo (CENTRA), Noviembre de 1999, San Salvador. 167 páginas.

12. Para ampliar al respecto de este apartado se recomienda consultar: "Impacto de las reformas del Código de Trabajo en el Ejercicio de los Derechos Laborales". Documento de investigación 2/96. Publicación del Centro de Estudios del Trabajo (CENTRA), San Salvador, agosto de 1996. 74 páginas. Pronunciamientos: 
de la empresa privada "La Cámara de Comercio e Industria de El Salvador expresa la verdad sobre el Foro"; del Gobierno de El Salvador: "Posición ante los Convenios de la Organización Internacional del Trabajo, tratados durante el Foro de Concertación Económica y Social", ambos publicados en la Revista de Estudios Centroamericanos, ECA No. 534-535. Meses de abril-mayo de 1993. UCA Edicores, San Salvador, Pág. 495-498. Artículo: "Libertad sindical, tratados internacionales y Constitución”. Huertas Bartolomé, Tebelia. Revista Estudios Centroamericanos ECA No. 537-538. Meses de julio-agosto de 1993. UCA Editores, San Salvador, Pág. 657-675.

13. Al respecto se puede consultar las siguientes notas periodísticas: "Seguridad de aeropuerto en manos del Ejército y PNC". La Prensa Gráfica del día 25 de septiembre del año 2001; Pág. 14 y 15.

14. Se puede consultar las siguientes notas periodísticas: “Siete empresas prestan servicio al Puerto. Cambio total en puerto de Acajutla". La Prensa Gráfica del día sábado 2 de febrero del año 2002, Pág. 30.

15. Al respecto se puede consultar las siguientes notas periodísticas: "Trabajadores de LIDO suspenden labores" CoLatino del día martes 7 de mayo del 2002, Pág. 5. "Trabajadores de LIDO se mantienen en paro". CoLatino del día miércoles 8 de mayo del 2002, Pág. 4. "Trabajadores piden ser restituidos. LIDO despide a 41 sindicalistas", CoLatino del día sábado 11 de mayo del 2002, Pág. 3. 